\title{
1 Vegetation baseline phenology from kilometric global LAI satellite
}

\section{products}

${ }^{1}$ CREAF, Cerdanyola del Vallès 08193, Catalonia, Spain

${ }^{2}$ CSIC, Global Ecology Unit, Cerdanyola del Vallès 08193, Catalonia, Spain

${ }^{3}$ INRA UMR114 EMMAH, Domaine Saint-Paul, 84914 Avignon, France

* Corresponding author: E-Mail: verger@creaf.uab.cat; Tel.: + 34- 935-813-008; Fax: +34-935814-151.

\section{Abstract}

Land surface phenology derived from remotely sensed satellite data can substantially improve our macroecological knowledge and the representation of phenology in earth system models. We characterized the baseline phenology of the vegetation at the global scale from the GEOCLIM climatology of leaf area index (LAI) estimated from 1-km SPOT-VEGETATION time series for 1999-2010. The phenological metrics were calibrated over an ensemble of ground observations of the timing of leaf unfolding and autumnal colouring of leaves. The start and end of season were best identified using respectively $30 \%$ and $40 \%$ threshold of LAI amplitude values. The accuracy of the derived phenological metrics, evaluated using available ground observations for birch forests over Europe (and lilac shrubs over North America), improved as compared to those derived from MODIS-EVI and produced an overall root mean square error of 7 days (19 days) for the timing of the start of season, 15 for the end of season, and 16 for the length of season. The spatial patterns of the derived LAI phenology agreed well with those from MODIS-EVI and -NDVI, although the 
timing of the start, end, and length of season differed by about one month at the global scale, with higher uncertainties in areas of limited seasonality of the satellite signal and systematic biases due to the differences in the methodologies and datasets. The baseline LAI phenology was spatially consistent with the global distributions of climatic drivers and biome land cover.

Keywords: Climatology of land surface phenology; mean annual seasonal cycle; leaf area index; SPOT-VEGETATION; MODIS; ground observations; climatic drivers

\section{Introduction}

Phenology describes the timing of the several phases of life cycle of organisms including recurrent transitions of vegetation through states of dormancy, active growth, and senescence. Phenology is a key regulator of processes in terrestrial ecosystems, including carbon, water, and nutrient cycling (Richardson et al. 2013). Phenological feedbacks may alter the seasonal climate through their effects on biogeochemical processes (especially photosynthesis and carbon sequestration) and the physical properties (mainly surface energy and water balance) of vegetated land surfaces (Bali and Collins 2015; Peñuelas et al. 2009). Land models coupled to global climatic models describe the exchanges of energy, water, and greenhouse gases between the land surface and the atmosphere using the leaf area index (LAI). Levis and Bonan (2004) highlighted the importance of accurate prognostic modelling of LAI dynamics for improving climatic simulations by atmospheric generalcirculation models coupled to land-surface schemes.

The representation of phenology in state-of-the art models of the terrestrial biosphere, including the soil/vegetation/atmosphere transfer schemes used in earth-system models, tends to be poor (Richardson et al. 2012). Models usually overestimate mean annual LAI and predict too long growing seasons because of delayed ends of the growing seasons in all biomes (Anav et al. 2013; Murray-Tortarolo et al. 2013; Zhu et al. 2013). Phenological models are most deficient for subtropical and Mediterranean vegetation, with a temporal mismatch in spring green up of 1-2 
months, because model parameters are often generalized from temperate vegetation to global scales (Stöckli et al. 2008). Models of widely studied temperate forests, however, tend to predict an excessively early start of season (one month or more) and a later end of season (up to two months), resulting in a substantially longer growing season than the actually observed one (Richardson et al. 2012). This overestimation produces large biases in the modelled seasonality of ecosystem processes and biosphere feedbacks to the climate system that are phenologically mediated (Richardson et al. 2013).

Vegetation phenology has been assessed though a variety of methods (White et al. 2009), including (1) ground observations of species-specific phenological events based on periodic visual inspection by scientists or by citizens (e.g. USA National Phenology Network www1, Pan European Phenology network www2, and Canadian PlantWatch project www3), (2) eddy covariance flux towers (Melaas et al. 2013), (3) phenology modeling (Chuine et al. 2000), (4) close range remote sensing based on digital cameras and spectral radiometers (e.g. USA PhenoCam network www4, and Phenological Eyes Network www5), and (5) satellite remote sensing such as this study. Satellite sensors with medium to coarse spatial resolution and frequent observations capture signals that can be exploited to improve our understanding on land surface processes including progress in the representation of phenology in terrestrial biosphere models (Demarty et al. 2007; MacBean et al. 2015; Stöckli et al. 2011) at the typical model grid cell spatial resolution $\left(0.5 \times 0.5^{\circ}\right)$ where local ground-based data are more difficult to use (Penuelas et al. 2009). Land surface phenology derived from remotely sensed satellite data allows the modelling of spatially explicit phenological patterns related to climatic variability and provides a better understanding of the environmental drivers of phenology (De Beurs and Henebry 2005; Zhang et al. 2006; Zhang et al. 2014).

Satellite sensors with moderate spatial resolution, including AVHRR, SPOT-VEGETATION, and MODIS, provide long-term time series of observations that describe the patterns of land surface phenology at continental and global scales (Atzberger et al. 2013; Brown et al. 2012; Ganguly et al. 
2010; Maignan et al. 2008; Sobrino et al. 2013; Vrieling et al. 2013; Zhang et al. 2003). A broad variety of strategies have been designed to extract phenological metrics from satellite time series based on thresholds (Myneni et al. 1997; White et al. 1997), moving averages (Reed et al. 1994), first derivatives (Tateishi and Ebata 2004; White et al. 2009), inflection points in empirical equations (Moulin et al. 1997), conceptual-mathematical phenological models based on thermal time (De Beurs and Henebry 2005; Kaduk and Heimann 1996), maximum curvature of piecewise logistic functions (Zhang et al. 2003), spectral-frequency decomposition techniques (Bradley et al. 2007; Sakamoto et al. 2010; Verbesselt et al. 2010) and curve fitting (Jönsson and Eklundh 2002; Julien and Sobrino 2009). de Beurs and Henebry (2010) have comprehensively reviewed the current approaches for modelling land surface phenology. White et al. (2009) found large discrepancies of up to two months in the detection of the start of the season among several methods for extracting phenological timing.

In addition to the sensitivity to the phenological detection algorithm, the derived phenological metrics are also dependent on the sensor, processing chain, and satellite data set. Atzberger et al. (2013) reported large discrepancies in phenological metrics, particularly the start of season, derived from the GIMMS and MODIS data sets for normalized difference vegetation index (NDVI) using the same phenological detection algorithm. Extraction of phenological information is sensitive to the temporal (Pouliot et al. 2011; Zhang et al. 2009) and spatial (Fisher and Mustard 2007; Kovalskyy et al. 2011) resolution of the satellite data. Noise and missing data due to cloud or snow contamination or to atmospheric or directional residual effects can also introduce significant uncertainties in the estimation of phenological metrics (Jönsson and Eklundh 2002; Kandasamy et al. 2013; Verger et al. 2013). The choice of the method for smoothing and gap filling the data can have a large impact on the accuracy of the phenology extracted from the reconstructed time series (Atkinson et al. 2012; Hird and McDermid 2009; Kandasamy et al. 2013; Verger et al. 2013). 
Most previous approaches for estimating phenological phases have been based on the use of spectral vegetation indices, which are proxies of vegetation biophysical variables. The different vegetation indices vary in their strength of phenological prediction across sites and plant functional types (Wu et al. 2014). (White et al. 2014) showed that the most commonly used NDVI and the enhanced vegetation index (EVI) outperformed other indices for the remote sensing of growing seasons in north-eastern American deciduous broadleaf and mixed forests, where the coincident timing of bud burst and snow melt may limit the use of the normalized difference water index (NDWI) and other indices based on mid-infrared wavelengths. The remote sensing of growing season in North American forests conducted by (Wu et al. 2014), however, suggested that the NDVI and EVI had limited potential predictive strength for evergreen needleleaf forests, while indices sensitive to water (e.g. NDWI) or less influenced by soil (the optimized soil-adjusted vegetation index) were stronger predictors.

Unlike previous studies based on vegetation indices, the aim of this study is to characterize the baseline phenology of leaf development from remotely sensed estimates of LAI at the global scale. LAI is more sensitive than vegetation indices such as NDVI to larger amounts of vegetation (Baret and Guyot 1991; Myneni and Williams 1994). This is particularly important to characterize the later stages of canopy development and leaf maturity (Huete et al. 2002; White et al. 2014). LAI estimation is also expected to be more robust across sensors than are vegetation indices, which are dependent on the band characteristics of each sensor (Steven et al. 2015). This is a major issue for phenological studies because the asymmetric changes in leaf pigmentation (e.g. leaf senescence in autumn) during the year may accentuate the differences in the band settings between different sensors (Atzberger et al. 2013). This may be better handled by estimates of biophysical products such as LAI using radiative transfer model inversion techniques. Finally, the phenology derived from LAI is expected to be more closely related to actual ground observations because it is based on leaf development rather than on proxies provided by vegetation indices which are not driven solely 
by the amount of leaves but also by the canopy structure and the biochemical composition of the existing foliage (Richardson et al. 2009).

We used mean LAI seasonal values derived from the time series rather than focusing on a particular year of observation to mitigate the noise in satellite data and to avoid possible artefacts introduced by the use of curve-fitting or filtering methods. The climatology of the data defined as the mean annual seasonal cycle can better cope with high occurrence of missing data in the satellite time series, leading to improved estimation of phenological metrics (Guyon et al. 2011; Kandasamy et al. 2013; Verger et al. 2013). The climatology derived from time series of moderate spatial resolution sensors preserves the high temporal frequency mandatory for phenological studies (Guyon et al. 2011). We used the mean seasonal LAI values derived from 12 years of SPOT-VEGETATION observations at a spatial resolution of $1 \mathrm{~km}$ (actually $0.009^{\circ}$ but termed $1 \mathrm{~km}$ resolution for the sake of simplicity) to characterize the baseline phenological patterns at a global scale. The main assumptions were that (i) the period of interest had no land-cover change or abrupt disturbance at the $1 \mathrm{~km}$ spatial resolution leading to a change in the phenological annual cycle and (ii) the time series were sufficiently long to encompass anomalies.

We will first describe the methodology for retrieving a global climatology of land surface phenology from SPOT-VEGETATION LAI. We will then assess the accuracy of the derived LAIbased phenological phases by comparison with available ground observations and the MODIS phenological products derived from the EVI and the NDVI, with due attention to the differences in the definitions of the phenological metrics. Finally, we will analyze the climatic drivers of the spatiotemporal patterns of the satellite and observed phenology.

\section{Materials and methods}

We used the GEOCLIM climatology of LAI (hereafter GEOCLIM-LAI) derived as the inter-annual means of 12-year of SPOT-VEGETATION observations (Verger et al. 2015). We then computed 
specific phenological metrics based on the seasonal LAI development. The input data and the steps required to predict the climatology of land surface phenology are first described. The ground-based observations used for the validation of the GEOCLIM-LAI phenology, the MODIS phenological products, and the climatic data, are then described. Finally, the approach for evaluating the methods and the associated metrics used is described.

\subsection{GEOCLIM-LAI climatology: mean annual seasonal cycle}

GEOCLIM (Verger et al. 2015), a global climatology of LAI, FAPAR, and fraction of vegetation cover (FCOVER), was derived as the interannual mean of the GEOV1 Copernicus Global Land time series of SPOT-VEGETATION biophysical products (Baret et al. 2013). GEOCLIM and the derived phenology take advantage of the improvements in accuracy and temporal consistency (smoothness) provided by GEOV1 over existing products (Camacho et al. 2013). GEOV1 products are very little affected by the recently detected bug in Sun-Earth distance calculation for SPOTVEGETATION (Baret et al. 2013). This is clearly demonstrated for the bare soil situation where, as expected, no seasonality is observed (Verger et al. 2015). This is also supported by the fact that the biophysical products are actually more sensitive to the relative reflectance values (as are most vegetation indices that are ratios of reflectances) than to the absolute value as demonstrated by Verger et al. (2014).

The GEOCLIM-LAI product was here considered to describe the baseline characteristics of the seasonal cycle of the annual vegetation phenology for each pixel on the globe. GEOCLIM-LAI was computed every 10 days at a spatial resolution of $0.009^{\circ}$ with a plate-carrée projection as the average for a given date across all years of the GEOV1 time series for 1999-2010 (Baret et al. 2013). A temporal smoothing and gap-filling (TSGF) technique (Verger et al. 2011) was applied in GEOCLIM-LAI to correct artefacts, especially when the LAI products were systematically unavailable across the years due to cloud coverage, which has a large impact on the accuracy of the 
derived phenological metrics (Kandasamy et al. 2013). Specific corrections based on the expected seasonality were applied to cloudy tropical evergreen broadleaf forests and high northern latitudes with poor levels of illumination where the low number of available observations compromised the reliability of the estimates (Verger et al. 2015).

GEOCLIM-LAI was demonstrated to be consistent, both spatially and temporally, with the climatologies of LAI derived from MODIS (Samanta et al. 2011), GIMMS3g (Zhu et al. 2013) and ECOCLIMAP (Champeaux et al. 2005; Faroux et al. 2013). GEOCLIM-LAI showed absolute differences lower than 0.5 compared with MODIS (GIMMS3g) LAI for more than $80 \%(90 \%)$ of land pixels. Further details of the implementation and quality assessment of GEOCLIM-LAI are provided in (Verger et al. 2015). We focus here on the climatology of land surface phenology as derived from GEOCLIM-LAI.

\subsection{Computation of phenological metrics}

The smoothed GEOCLIM-LAI annual time series were linearly interpolated at the daily time step for the computation of phenology in day units. The annual LAI time series were repeated threetimes and we focused our analysis in the central period to prevent border effects in the beginning and the end of the year. A number of phenological metrics were computed from GEOCLIM-LAI (Figure 1):

- The amplitude of GEOCLIM-LAI defined as the difference between the maximum and minimum LAI values over the growth cycle.

- The number of growing seasons per year was retrieved as the number of peaks identified in GEOCLIM-LAI. A point was considered as a maximum peak if it had the maximum value and was preceded by a value lower than $\delta$, where $\delta=\max (0.1$, 0.3*annual_median(GEOCLIM-LAI)). For pixels with multiple growing seasons, we 
computed the phenological metrics for the growing season having the highest LAI amplitude. Phenological metrics were not computed for pixels with any growing season.

- The peak of the growing season corresponding to the timing of maximum foliar development (Brown et al. 2012; Jönsson and Eklundh 2002) when GEOCLIM-LAI reached its maximum value over the annual cycle.

- The start of season (SoS) was defined as the date for which GEOCLIM-LAI rise to a given percentile of its amplitude (Jönsson and Eklundh 2002; White et al. 1997), or the date of the maximum of the first derivative (White et al. 2009). The performances of these different definitions of the SoS will be compared with ground observations to select the most pertinent one. Results will be presented in section 3.2.

- The end of season (EoS) was computed as the date for which GEOCLIM-LAI descent to a given percentile of its amplitude, or the date of the minimum of the first derivative .

- The length of season (LoS) was defined as the length of the period between the EoS and the SoS.

\section{[Figure 1]}

\subsection{Ground data}

The validation of GEOCLIM-LAI baseline phenology is particularly difficult since multi-annual ground-truth measurements of the same site and phenophase for the period 1999-2010 are rarely available. After an extensive review of the literature and exploration of the available phenology datasets, we used ground-based phenological observations for lilac (Syringa vulgaris) from USA National Phenology Network (open access data set at www1) and birch (Betula pendula) from the PEP725 Pan European Phenology data (www2). These data sets are unique in both its geographic and temporal coverages. They consist of data collected by volunteers on a weekly basis up to every day depending on the season (Koch et al. 2007; Olsson and Jönsson 2014; Rosemartin et al. 2015). 
215 We only included sites with at least three years of measurements for 1999-2010. These ground measurements represent phenological phases for a limited number of individual plants that are not necessarily representative of the areal coverage of the 1-km SPOT-VEGETATION satellite pixel (Liang et al. 2011). The spatiotemporal-scale mismatch with field data is a major source of uncertainty in satellite phenological assessments (White et al. 2009). The phenology of each species influence the satellite signal depending on its abundance within the pixel sampling area but also on the timing of their phenophases (Delbart et al. 2015). SoS based on remote sensing may mainly reflect the spring phenology of some early spring species in the study regions (Fu et al. 2014), so $B$. pendula was chosen because it is an early spring species with higher representation in the areas examined. Since vegetation phenology occurs in response to seasonal variations of climatic variables land surface phenology can highly correlate with non-abundant species (Delbart et al. 2015). S. vulgaris was used because its phenology is strongly controlled by temperature (Schwartz and Reiter 2000) although it is not a dominant species over large areas (Maignan et al. 2008). Similarly to (Delbart et al. 2015), we excluded sites classified as pure agriculture or water, based on GLOBCOVER (Defourny et al. 2009) land-cover map.

The S. vulgaris dataset consists in leafing data collected across the continental United States from 1956 to 2014 (Rosemartin et al. 2015). We used data from 1999 for the full leaf phenophase, defined as the timing when nearly all (at least 95\%) of the actively growing leaf buds have already leafed, and representing the SoS. The selected ground measurements of S. vulgaris in USA are distributed from the west coast to the east coast covering a south-north latitudinal gradient from to $35.1^{\circ}$ to $48.1^{\circ}$ (Figure $\left.2 \mathrm{a}\right)$.

237 from $45.9^{\circ}$ to $68.4^{\circ}$ (Figure 2 b). We used observations from Finland, Lithuania, Germany, Slovenia 238 and Croatia (Figure 2b). The German data set was extensive, so we selected randomly only 30 sites. The observations were (i) the day of budburst, defined as leaf unfolding on the first visible leaf stalk 
and representing the SoS (for Lithuania the observed phenophase representing SoS was the mouseear stage, i.e. the timing of the first leaves separating), and (ii) 50\% autumnal colouring of leaves and representing the EoS. The LoS was computed as the length of the period between the EoS and the SoS.

\section{[Figure 2]}

\subsection{MODIS phenology products}

The MODIS-EVI phenology product (MCD12Q2 Collection 5) (Ganguly et al. 2010; Zhang et al. 2003) was used for comparison. MODIS-EVI provided yearly global vegetation phenologies at 500 m spatial resolution for the 2001-2010 period. The method used a series of piecewise logistic functions that were fitted once a year to the 16-day EVI data. More formally, the temporal variation of the EVI was modelled using a sigmoidal function:

$$
y(t)=\frac{c}{1+e^{a+b t}}+d
$$

where $t$ is time in days, $y(t)$ is the EVI value at time $t, a$ and $b$ are fitting parameters associated with the timing and rate of change in the EVI, respectively, $c+d$ is the maximum modelled EVI value, and $d$ is the initial background EVI value. The inflection points in the rate of change in the curvature of the fitted logistic model identified the phenological transition dates (Zhang et al. 2003). The MODIS-EVI phenology product provided the transition dates for vegetation activity and information about the EVI values on these dates for two growth cycles per year for each pixel. For each seasonal cycle, the onset of the increase in greenness (greenup), greenness maximum (maturity), greenness decrease (senescence), and greenness minimum (dormancy) were provided.

Note that the MODIS-EVI definition differs from the phenological metrics proposed here for GEOCLIM-LAI. The GEOCLIM-LAI SoS would correspond to the MODIS-EVI greenup, the EoS to the dormancy, and the peak would be within the maturity and the senescence but with no exact correspondence with the MODIS-EVI metrics. (Verger et al. 2015) showed that the peak of 
maximum leaf development from GEOCLIM-LAI occurred 14 days later than the MODIS-EVI maturity date due to the differences in the definitions and the use of LAI instead of EVI. We assessed the influence of the differences in the definitions of the phenological metrics in section 3.3. In addition to the MODIS-EVI phenology products, we used the MODIS-NDVI phenological parameters derived by (Butt et al. 2011) using a double-logistic function fitted to seasonal NDVI trajectories for MODIS data. The MODIS-NDVI SoS is defined as the maximum of the second derivative, the EoS as the first date after maximum NDVI when the NDVI falls to $80 \%$ of its maximum value, and the $\operatorname{LoS}$ as the difference (in days) between the EoS and the SoS (Butt et al. 2011). We used the means of the SoS, EoS and LoS for MODIS-NDVI phenological variables across the 2000-2010 period for $0.25^{\circ}$ latitude bands in Sudano-Sahelian West Africa as reported by (Butt et al. 2011). Results of the comparison between MODIS-NDVI and GEOCLIM-LAI latitudinal gradients of Sahelian phenology are presented in section 3.4.

\subsection{Temperature, short-wave radiation and rainfall data}

To interpret phenological patterns observed with the possible climatic drivers, we used the WFDEI (WATCH Forcing Data methodology applied to ERA-Interim data) meteorological data, which is based on WATCH forcing data methodology applied to the ERA-Interim reanalysis data (Weedon et al. 2014). We used the daily average air temperature at $2 \mathrm{~m}$, the short-wave downwards surface radiation $\left(\mathrm{W} / \mathrm{m}^{2}\right)$ and the rainfall rate (cumulative $\mathrm{mm}$ ) generated by using the Global Precipitation Climatology Centre (GPCC) precipitation totals (Schneider et al. 2014). WFDEI data were available for the global land surface at a spatial resolution of $0.5^{\circ}$ from January 1979 to December 2012 .

\subsection{Evaluation approach}

Because of the importance of the number of growing seasons and LAI amplitude for the understanding of LAI phenology, these two sub-products of the GEOCLIM-LAI will first be 
described (section 3.1). The approach proposed for the evaluation of GEOCLIM-LAI phenology is based on three steps as sketched in Figure 3. The several definitions of the SoS, EoS and LoS phenology metrics will be evaluated by comparison with the available ground measurements (section 3.2). This will also provide some element of the validation of the phenology products proposed. Then these phenology products will be compared to those derived from MODIS (section 3.3). Finally, the spatial patterns of phenological leaf development from satellite and ground data will be assessed with due attention to the latitudinal gradients in Europe and African Sahel and the possible climatic drivers (section 3.4).

The climatology of land surface phenology derived from GEOCLIM-LAI was compared with the climatologies derived from ground and MODIS phenologies as the interannual means (Figure 3). The assessment was performed from $1 \mathrm{~km}$ to $0.5^{\circ}$ spatial resolutions. The comparison of GEOCLIM-LAI phenological metrics with ground observations (section 3.2) was achieved at the original 1-km spatial resolution of VEGETATION-SPOT data. The latitudinal gradients of GEOCLIM-LAI phenological climatologies (section 3.4.) in the Sahel region were compared to the MODIS-NDVI transects available at $0.25^{\circ}$ spatial resolution. Finally, the comparison with MODISEVI derived phenology (section 3.3) and the analysis of climatic drivers (section 3.4) was performed at a spatial sampling of $0.5^{\circ}$ that corresponds to the typical resolution of global models. For comparison purposes, we first computed a climatology of ground phenology based on the interannual average of ground-based values for SoS, EoS, and LoS (Figure 3). Similarly, the yearly MODIS-EVI derived phenology data were averaged over the 2001-2010 period to provide a climatology of phenological stages. The MODIS-EVI 500-m original products were then projected on $1-\mathrm{km}$ and $0.5^{\circ}$ plate carrée system using the cubic convolution technique as implemented in the MODIS reprojection tool. We used the MODIS-NDVI climatology of Sahelian land surface phenology from 2000 to 2010 at $0.25^{\circ}$ spatial resolution as proposed by (Butt et al. 2011). We aggregated the $0.009^{\circ}$ (about $1-\mathrm{km}$ at the equator) GEOCLIM-LAI phenological products at $0.25^{\circ}$ 
and $0.5^{\circ}$ spatial resolutions for comparison with MODIS-NDVI and -EVI phenologies, respectively. Finally, we computed a climatology for air temperature, short-wave radiation and cumulative rainfall by averaging WFDEI daily data at $0.5^{\circ}$ spatial resolution for the interpretation of the climatic drivers of the GEOCLIM-LAI phenological patterns.

[Figure 3]

\section{Results and discussion}

\subsection{Number of growing seasons and LAI amplitude}

The amplitude of GEOCLIM-LAI (Figure 4a) reflected the expected regimes of vegetation at the global scale in agreement with the global distribution of biomes with maximum values around the mid-northern latitudes as well as around $10^{\circ}$ latitude in Africa. Most of the other places showed LAI amplitude values lower than 2. The number of growing seasons (Figure 4b) was set to zero in areas that exhibited null seasonality (Figure 4a): deserts with LAI 0 and evergreen broadleaf forests in the tropical belt with LAI 5 throughout the year (Verger et al. 2015). Two growing seasons were identified in agricultural areas with two crop cycles per year (e.g. rice plantations in India, China, and the Nile delta) and in the Horn of Africa, which had a bimodal precipitation regime with two wet seasons per year (Vrieling et al. 2013). Bimodal LAIs also corresponded to areas where leaf development is constrained by both temperature in winter and water availability in summer (Julien and Sobrino 2009). Other isolated areas with multiple growing seasons may indicate artefacts in the data set.

[Figure 4] 
The dates of SoS, EoS and LoS for GEOCLIM-LAI derived phenology products computed with several possible definitions were compared with the ground-based observations for birch $(B$. pendula) forests and lilac (S. vulgaris) shrubs. Note that the places where ground based measurements were taken (Figure 2) correspond to single growth cycle areas (Figure 4b). Results show that the best performances for SoS were obtained for the $30 \%$ threshold value that provided the smallest bias and root mean square error (RMSE) values (Table 1). However, this optimal definition of the SoS provided poorer performances in terms of RMSE for the EoS for which a threshold value of $40 \%$ better matched ground observations (Table 1) (Nagai et al. 2014). As a matter of facts, the ground data corresponded to $50 \%$ autumnal colouring of leaves. Nevertheless, a higher variability across the canopy of the timing and rate of leaf development is expected in autumn than in spring (Richardson et al. 2009). This translates by a higher RMSE and lower correlation $R$ values for EoS as compared to the SoS (Table 1). The LoS computed as the distance between the EoS and SoS using, respectively, the $40 \%$ and $30 \%$ threshold values provided the best performances (Table 1) and it was retained as the proposed definition for GEOCLIM-LAI phenological metrics.

\section{[Table 1]}

The agreement between GEOCLIM-LAI SoS date using the 30\% threshold value (Figure 5) with leafing ground observations of $B$. pendula (respectively S. vulgaris) produced an overall RMSE of 7 (resp. 19) days, a bias of only 1 (resp. -3) day and correlated significantly (correlation coefficient $\sim 0.9$ (resp 0.5)) (Table 1). The performances decreased for the date of the EoS using the $40 \%$ threshold value, with an RMSE of 15 days and a positive bias (delay) of about 7 days. The performances for LoS (RMSE of 16 days) were mainly limited by those for EoS, with 6 days longer LoS for GEOCLIM-LAI as compared to the ground observations. 
The higher uncertainty in the estimation of the date for EoS as compared to the SoS can be explained by multiple factors. The environmental (day length, temperature, rainfall) and internal (plant age, photosynthetic rate and other leaf traits) causes of the timing of leaf coloration in autumn are less understood and have a higher interspecific (and among individual plants) and interannual variability than leaf-out phenological phases (Archetti et al. 2013; Estrella and Menzel 2006; Richardson et al. 2009). Leaf colouring corresponds to various changes in chemical and structural properties, resulting in changes in spectral responses, which may start long before leaf abscission while leaf appearance is much more well defined in time (Delbart et al. 2005). In addition there is higher uncertainty associated both to ground measurements and satellite products for autumn phenology (Nagai et al. 2014). The timing of 50\% of all leaves colouring is obviously more difficult to identify by ground observers than the timing of leaf unfolding or other spring phenophases (Estrella and Menzel 2006). Finally, the satellite products and the derived phenology at high latitudes in autumn are affected for atmospheric effects, snow and poor illumination conditions (Delbart et al. 2005; Verger et al. 2015).

The phenological metrics derived from MODIS-EVI showed poorer agreement with ground observations, with higher RMSE and lower $R$ values (Table 1, Figure 5). The MODIS derived phenology presented a negative bias (advance) of 12 (21) days for the timing of the SoS as compared to B. pendula (S. vulgaris) ground measurements and a positive bias (delay) of about 25 days for the timing of the EoS which resulted in 38-day longer LoS.

\section{[Figure 5]}

\subsection{Comparison with MODIS-EVI phenology}

The SoS and EoS derived from GEOCLIM-LAI were globally consistent with those derived from MODIS-EVI with a correlation coefficient larger than 0.84 (Table 2) with however a RMSE of 30 days and a bias around 9 days later for GEOCLIM-LAI SoS and 12 days earlier for GEOCLIM-LAI 
EoS (Table 2). They vary widely as a function of space (Figure 6) and biome type (Table 2). The analysis per class (Table 2) showed higher differences for shrubs-savannah and crops-grassland compared to forest classes. Crop and grassland biome types showed the largest RMSE values (Table 2). This may be due to the higher interannual variability of agricultural and grassland areas (Verger et al. 2015) that degrades the representativeness of the computed climatologies. The largest systematic differences (Figure 6) appear concentrated in areas of low LAI amplitude (Figure 4a). This is clearly illustrated by Figure 7a: the differences in the SoS decreased as a function of the amplitude of LAI and converged to a positive bias of about 9 days. These systematic differences are mainly due to differences in the definition of the phenological metrics as demonstrated by a simple theoretical study: a range of EVI time series based on the logistic function described in Eq. 1 were first simulated by varying the rate of change (parameter $b$ varying from -1 to 0 ), and fixing parameters $[a, c, d]$ to $[10,0.6,0.1]$ (Zhang et al. 2004). The simulated EVI was transformed into LAI using the exponential relationship proposed by Huete et al. (2002). Finally, the MODIS-EVI phenological metrics corresponding to the inflection points in the EVI time series, was compared to that of GEOCLIM-LAI corresponding to the 30\%-percentile of LAI amplitude. Results (Figure 7b) confirmed that the SoS phenological phase retrieved from the GEOCLIM-LAI was expected to occur later than the MODIS-EVI one and that these positive differences increased for the pixels having low seasonality (rate of change near zero). Similar reasoning could be applied to the EoS stage.

The agreement between the phenology derived from GEOCLIM-LAI and MODIS-EVI degraded for the LoS because of the combination of the uncertainties associated both with the SoS and the EoS. The LoS retrieved from GEOCLIM-LAI was thus shorter than the LoS retrieved from MODIS-EVI (bias of -22 days, Table 2; the dominant blue tones in Figure 6c indicate a negative bias). 


\subsection{Spatial patterns of satellite and ground-based phenology}

408 The spatial pattern of the derived global phenology (Figure 8) reflected the distributions of climatic 409 drivers and biomes. The observed relationship between phenological patterns and latitudinal 410 climatic drivers was not uniform but spatially dependent because of the interactions between 411 climate, vegetation functioning, and the distribution of species (Forkel et al. 2014; Iio et al. 2014; 412 Verger et al. 2015; Zhang et al. 2004). In addition, latitudinal variation in the phenology of leaf 413 development has a strong genetic component associated partly with variation in the photoperiod 414 (Friedman et al. 2011). Leaf lifespan is highly correlated with other leaf traits such as leaf mass per unit area, nitrogen content and photosynthetic rate (Wright et al. 2004) and reflect a trade-off between production efficiency and persistence of plant leaves (Reich et al. 1991). Phenology may control many feedbacks of vegetation to the climate system by influencing the photosynthesis and carbon sequestration (Peñuelas et al. 2009; Richardson et al. 2013).

The cumulative annual rainfall was highly correlated with the LoS across latitudes $<40^{\circ}$ (Figure 9). The LoS in the Southern Hemisphere from $35^{\circ} \mathrm{S}$ to $0^{\circ}$ increased from 150 to 230 days as the cumulative annual rainfall increased from 500 to $1500 \mathrm{~mm}$. LoS decreased steeply from $0^{\circ}$ to $15^{\circ} \mathrm{N}$, corresponding to the negative south-to-north gradient in rainfall in the Sahel region where water availability is the main limiting factor of leaf development. The latitudinal pattern was more complex from $15^{\circ} \mathrm{N}$ to $40^{\circ} \mathrm{N}$ due to averaging the LoSs of different phenological regimes driven by the conditions of climatic regions ranging from tropical to Mediterranean. LAI phenology for northern latitudes $>40^{\circ}$ was strongly dependent on the mean annual temperature, the short-wave radiation and the cumulative rainfall which are intrinsically correlated and decrease linearly with 
latitude. SoS (respectively EoS) had a clear and smooth negative (resp. positive) latitudinal gradient corresponding to a delay (resp. advance) in the timing of SoS (resp. EoS) (Figure 8), which led to a decrease of LoS with latitude (Figure 9).

\section{[Figure 9]}

The climatology of land surface phenology derived from GEOCLIM-LAI over the European continent (Figure 10a) showed a good agreement with existing average phenologies derived from MODIS or AVHRR NDVI data (Atzberger et al. 2013). GEOCLIM-LAI phenology accurately reproduced latitudinal patterns provided by the ground observations, with a delay of 50 days in the SoS and a similar advance of 50 days in the EoS from $45^{\circ}$ to $70^{\circ}$ northern latitudes (Figure 11 a). This corresponds to a latitudinal gradient of $\operatorname{LoS}$ around 100 days (Figure 11a) matching a temperature gradient of about $10{ }^{\circ} \mathrm{C}$, i.e. a rate of change of 10 days $/{ }^{\circ} \mathrm{C}$. The rate of change in the LoS in the European birch forests, estimated from both ground observations and satellite LAI, was about four days per latitude degree of latitude which resulted from symmetric variations of two days per latitude degree in the SoS and EoS.

LAI phenology in the African Sahel (Figure 10b) reflected the negative south-to-north gradient in rainfall with later SoS and earlier EoS resulting in a steeply decrease of LoS with latitude (Figure 11b). Good agreement was achieved between GEOCLIM-LAI and MODIS-NDVI latitudinal gradients of phenology in Sudano-Sahelian region from $12^{\circ}$ to $17^{\circ} \mathrm{N}$ (Figure $11 \mathrm{~b}$ ) with non-linear latitudinal pattern characterized by sharpest variations of SoS for the lower latitudes and a more limited variation of EoS with latitude. This results in a rate of change in the LoS of about 15 days per latitudinal degree. The systematic biases observed between GEOCLIM-LAI compared to MODIS-NDVI (Figure 11b) are mainly due to the differences in the definition of phenological metrics as demonstrated previously (Section 3.2) and in agreement with Butt et al. (2011).

[Figure 10]

[Figure 11] 
455 The baseline phenology of vegetation was described at the global scale from the mean annual 456 seasonal cycle depicted by GEOCLIM-LAI — a global climatology of leaf area index (LAI) derived from the average values over twelve years of SPOT-VEGETATION observations at a spatial resolution of 1-km for 1999-2010.

The calibration of the phenological metrics over actual ground observations indicated that the $30 \%$ threshold on the LAI amplitude is optimal for the detection of the start of season while a $40 \%$ threshold is more appropriate for the end of season. The accuracy for the start of season evaluated using ground observations, produced an overall RMSE of 7 days for the date of leaf unfolding for European birch forests and 19 days for North American lilac shrubs. A higher uncertainty of 15 days was found for the end of season which resulted in deviations of 16 days for the length of season of birch forests. Further investigations should be pursued to better define the threshold values by including more ground observations with a wider range of species and a broader spatial extent in latitude and longitude. This should ultimately lead to propose a standardisation of the phenological metrics.

The GEOCLIM-LAI phenology was highly spatially consistent and significantly correlated (R>0.8) with the phenology derived from MODIS-EVI time series, but with differences of about one month in terms of RMSE for the start and end of season, and 40 days for the length of season. These differences were mostly driven by random errors in regions with limited seasonality (LAI amplitude 0) but also by systematic biases due to the differences in the methodologies and datasets. The phenology derived from GEOCLIM-LAI constituted an intermediate solution between those from MODIS-EVI and ground observations.

The GEOCLIM-LAI phenology reflected the expected regimes of the baseline annual cycle of the vegetation seasonality at the global scale, in agreement with the global distribution of biome land cover and climatic drivers. Phenological spatial patterns were complex at latitudes $<40^{\circ}$ due to the 
heterogeneity in the species composition and climate drivers, but the length of season was clearly correlated with the annual cumulative rainfall. Soil moisture is the main driver of phenology in water-limited vegetation, but evapotranspiration and soil characteristics that control water retention should be included for a better understanding of the vegetation dynamics in these regions. The timing of phenological leaf development at northern latitudes $>40^{\circ}$ were highly correlated with the latitudinal decay in mean annual temperature, solar short-wave radiation and cumulative rainfall. Disentangling the contribution of climatic drivers and establishing the mechanisms that govern the latitudinal patterns of vegetation phenology at the global scale would require further analysis taking the interannual variations into account.

The latitudinal gradients of phenological leaf development from GEOCLIM-LAI and ground data in Europe agreed very well with a gradual decrease in the length of growing season of approximately four days per degree of latitude which resulted from symmetric variations of 2 days per degree in the start and end of season. The latitudinal pattern of the derived phenology metrics also agreed with those from MODIS-NDVI in African Sahel showing a much stronger rate of change of the length of season with latitude of about 15 days per degree of latitude.

Our baseline phenology derived from kilometric global LAI satellite products is expected to contribute to improve our macroecological knowledge and the representation of phenology in earth system models.

\section{Acknowledgements}

This research was partially supported by the European Earth observation programme Copernicus, le Pôle Thématique Surfaces Continentales THEIA, and the FP7 geoland2 (218795), GIOBIO (32566), and LONGLOVE (32-594) projects. This research was also supported by the Spanish Government grant CGL2013-48074-P, the Catalan Government grant SGR 2014-274, and the European Research Council Synergy grant ERC-2013-SyG-610028 IMBALANCE-P. Aleixandre 
Verger was the recipient of a Juan de la Cierva postdoctoral fellowship from the Spanish Ministry of Science and Innovation. The authors are indebted to Marie Weiss, the CNES, VITO and MODIS teams for providing access to the data. We also thank the volunteers that collected the phenology ground measurements and the teams who contributed to set up the PEP725 dataset.

\section{References}

www1: USA National Phenology Network

https://www.usanpn.org (Accessed February 1st 2016)

www2: Pan European Phenology Project PEP725

http://www.pep725.eu (Accessed February 1st 2016)

www3: PlantWatch project

https://www.naturewatch.ca/plantwatch (Accessed February 1st 2016)

www4: USA Phenocam Network

http://phenocam.sr.unh.edu/webcam (Accessed February 1st 2016)

www5: Phenologial Eyes Network

http://pen.agbi.tsukuba.ac.jp/index_e.html (Accessed February 1st 2016)

Anav, A., Murray-Tortarolo, G., Friedlingstein, P., Sitch, S., Piao, S., \& Zhu, Z. (2013). Evaluation of Land Surface Models in Reproducing Satellite Derived Leaf Area Index over the High-Latitude Northern Hemisphere. Part II: Earth System Models. Remote Sensing, 5, 3637-3661

Archetti, M., Richardson, A.D., O'Keefe, J., \& Delpierre, N. (2013). Predicting Climate Change Impacts on the Amount and Duration of Autumn Colors in a New England Forest. PLoS ONE, 8, e57373

Atkinson, P.M., Jeganathan, C., Dash, J., \& Atzberger, C. (2012). Inter-comparison of four models for smoothing satellite sensor time-series data to estimate vegetation phenology. Remote Sensing of Environment, 123, 400-417 
Atzberger, C., Klisch, A., Mattiuzzi, M., \& Vuolo, F. (2013). Phenological Metrics Derived over the European Continent from NDVI3g Data and MODIS Time Series. Remote Sensing, 6, 257-284 Bali, M., \& Collins, D. (2015). Contribution of phenology and soil moisture to atmospheric variability in ECHAM5/JSBACH model. Climate Dynamics, 1-8

Baret, F., \& Guyot, G. (1991). Potentials and limits of vegetation indices for LAI and APAR assessment. Remote Sensing of the Environment, 35, 161-173

Baret, F., Weiss, M., Lacaze, R., Camacho, F., Makhmara, H., Pacholcyzk, P., \& Smets, B. (2013). GEOV1: LAI, FAPAR Essential Climate Variables and FCOVER global time series capitalizing over existing products. Part1: Principles of development and production. Remote Sensing of Environment, 137, 299-309

Bradley, B.A., Jacob, R.W., Hermance, J.F., \& Mustard, J.F. (2007). A curve fitting procedure to derive inter-annual phenologies from time series of noisy satellite NDVI data. Remote Sensing of Environment, 106, 137-145

Brown, M.E., de Beurs, K.M., \& Marshall, M. (2012). Global phenological response to climate change in crop areas using satellite remote sensing of vegetation, humidity and temperature over 26 years. Remote Sensing of Environment, 126, 174-183

Butt, B., Turner, M.D., Singh, A., \& Brottem, L. (2011). Use of MODIS NDVI to evaluate changing latitudinal gradients of rangeland phenology in Sudano-Sahelian West Africa. Remote Sensing of Environment, 115, 3367-3376

Camacho, F., Cernicharo, J., Lacaze, R., Baret, F., \& Weiss, M. (2013). GEOV1: LAI, FAPAR Essential Climate Variables and FCOVER global time series capitalizing over existing products. Part 2: Validation and intercomparison with reference products. Remote Sensing of Environment, $137,310-329$

Champeaux, J.L., Masson, V., \& Chauvin, F. (2005). ECOCLIMAP: a global database of land surface parameters at $1 \mathrm{~km}$ resolution. Meteorological Applications, 12, 29-32 
552 Chuine, I., Cambon, G., \& Comtois, P. (2000). Scaling phenology from the local to the regional 553 level: advances from species-specific phenological models. Global Change Biology, 6, 943-952

554 De Beurs, K.M., \& Henebry, G.M. (2005). Land surface phenology and temperature variation in the 555 International Geosphere-Biosphere Program high-latitude transects. Global Change Biology, 11, $556 \quad 779-790$

557 de Beurs, K.M., \& Henebry, G.M. (2010). Spatio-Temporal Statistical Methods for Modelling Land 558 Surface Phenology. In I.L. Hudson, \& M.R. Keatley (Eds.), Phenological Research: Methods for 559 Environmental and Climate Change Analysis (pp. 177-208). London: Springer

560 Defourny, P., Bicheron, P., Brockmann, C., Bontemps, S., Van Bogaert, E., Vancutsem, C., Pekel, 561 J.F., Huc, M., Henry, C., Ranera, F., Achard, F., di Gregorio, A., Herold, M., Leroy, M., \& Arino, 562 O. (2009). The first $300 \mathrm{~m}$ global land cover map for 2005 using ENVISAT MERIS time series: a 563 product of the GlobCover system,. In, Proceedings of the 33rd International Symposium on Remote $564 \quad$ Sensing of Environment. Stresa (Italy)

565 Delbart, N., Beaubien, E., Kergoat, L., \& Le Toan, T. (2015). Comparing land surface phenology 566 with leafing and flowering observations from the PlantWatch citizen network. Remote Sensing of 567 Environment, 160, 273-280

568 Delbart, N., Kergoat, L., Le Toan, T., Lhermitte, J., \& Picard, G. (2005). Determination of 569 phenological dates in boreal regions using normalized difference water index. Remote Sensing of 570 Environment, 97, 26-38

571 Demarty, J., Chevallier, F., Friend, A.D., Viovy, N., Piao, S., \& Ciais, P. (2007). Assimilation of 572 global MODIS leaf area index retrievals within a terrestrial biosphere model. Geophysical Research 573 Letters, 34

574 Estrella, N., \& Menzel, A. (2006). Responses of leaf colouring in four deciduous tree species to 575 climate and weather in Germany. Climate Research, 32, 253-267 
576 Faroux, S., Kaptué Tchuenté, A.T., Roujean, J.L., Masson, V., Martin, E., \& Le Moigne, P. (2013). 577 ECOCLIMAP-II/Europe: a twofold database of ecosystems and surface parameters at $1 \mathrm{~km}$ 578 resolution based on satellite information for use in land surface, meteorological and climate models. 579 Geosci. Model Dev., 6, 563-582

580 Fisher, J.I., \& Mustard, J.F. (2007). Cross-scalar satellite phenology from ground, Landsat, and 581 MODIS data. Remote Sensing of Environment, 109, 261-273

582 Forkel, M., Carvalhais, N., Schaphoff, S., v. Bloh, W., Migliavacca, M., Thurner, M., \& Thonicke, 583 K. (2014). Identifying environmental controls on vegetation greenness phenology through model584 data integration. Biogeosciences, 11, 7025-7050

585 Friedman, J.M., Roelle, J.E., \& Cade, B.S. (2011). Genetic and environmental influences on leaf 586 phenology and cold hardiness of native and introduced riparian trees. International Journal of 587 Biometeorology, 55, 775-787

588 Fu, Y.H., Piao, S., Op de Beeck, M., Cong, N., Zhao, H., Zhang, Y., Menzel, A., \& Janssens, I.A. 589 (2014). Recent spring phenology shifts in western Central Europe based on multiscale observations. 590 Global Ecology and Biogeography, 23, 1255-1263

591 Ganguly, S., Friedl, M.A., Tan, B., Zhang, X., \& Verma, M. (2010). Land surface phenology from 592 MODIS: Characterization of the Collection 5 global land cover dynamics product. Remote Sensing 593 of Environment, 114, 1805

594 Guyon, D., Guillot, M., Vitasse, Y., Cardot, H., Hagolle, O., Delzon, S., \& Wigneron, J.-P. (2011). 595 Monitoring elevation variations in leaf phenology of deciduous broadleaf forests from 596 SPOT/VEGETATION time-series. Remote Sensing of Environment, 115, 615-627

597 Hird, J.N., \& McDermid, G.J. (2009). Noise reduction of NDVI time series: An empirical 598 comparison of selected techniques. Remote Sensing of Environment, 113, 248-258 
599

600

601

602

603

604

605

606

607

608

609

610

611

612

613

Huete, A., Didan, K., Miura, T., Rodriguez, E.P., Gao, X., \& Ferreira, L.G. (2002). Overview of the radiometric and biophysical performance of the MODIS vegetation indices. Remote Sensing of Environment, 83, 195-213

Iio, A., Hikosaka, K., Anten, N.P.R., Nakagawa, Y., \& Ito, A. (2014). Global dependence of fieldobserved leaf area index in woody species on climate: a systematic review. Global Ecology and Biogeography, 23, 274-285

Jönsson, P., \& Eklundh, L. (2002). Seasonality extraction by function fitting to timeseries of satellite sensor data. IEEE transactions on Geoscience and Remote Sensing, 40, 1824-1832

Julien, Y., \& Sobrino, J.A. (2009). Global land surface phenology trends from GIMMS database. International Journal of Remote Sensing, 30, 3495-3513

Kaduk, J., \& Heimann, M. (1996). A prognostic phenology scheme for global terrestrial carbon cycle models. Climate Research, 06, 1-19

Kandasamy, S., Baret, F., Verger, A., Neveux, P., \& Weiss, M. (2013). A comparison of methods for smoothing and gap filling time series of remote sensing observations: application to MODIS LAI products. Biogeosciences, 10, 4055-4071

Koch, E., Bruns, E., Chmielewski, F.M., Defila, C., Lipa, W., \& Menzel, A. (2007). Guidelines for phenological observations. WMO Technical Commission for Climatology, Open Program Area Group on Monitoring and Analysis of Climate Variability and Change (OPAG2). http://www.omm.urv.cat/documentation.html. Accessed February 1st, 2016

Kovalskyy, V., Roy, D.P., Zhang, X.Y., \& Ju, J. (2011). The suitability of multi-temporal webenabled Landsat data NDVI for phenological monitoring - a comparison with flux tower and MODIS NDVI. Remote Sensing Letters, 3, 325-334

Levis, S., \& Bonan, G.B. (2004). Simulating Springtime Temperature Patterns in the Community Atmosphere Model Coupled to the Community Land Model Using Prognostic Leaf Area. Journal of Climate, 17, 4531-4540 
Liang, L., Schwartz, M.D., \& Fei, S. (2011). Validating satellite phenology through intensive ground observation and landscape scaling in a mixed seasonal forest. Remote Sensing of Environment, 115, 143-157

MacBean, N., Maignan, F., Peylin, P., Bacour, C., Bréon, F.M., \& Ciais, P. (2015). Using satellite data to improve the leaf phenology of a global terrestrial biosphere model. Biogeosciences, 12, $7185-7208$

Maignan, F., Bréon, F.M., Bacour, C., Demarty, J., \& Poirson, A. (2008). Interannual vegetation phenology estimates from global AVHRR measurements: Comparison with in situ data and applications. Remote Sensing of Environment, 112, 496

Melaas, E.K., Richardson, A.D., Friedl, M.A., Dragoni, D., Gough, C.M., Herbst, M., Montagnani, L., \& Moors, E. (2013). Using FLUXNET data to improve models of springtime vegetation activity onset in forest ecosystems. Agricultural and Forest Meteorology, 171-172, 46-56

Moulin, S., Kergoat, L., Viovy, N., \& Dedieu, G. (1997). Global scale assessment of vegetation phenology using NOAA/AVHRR satellite measurements. Journal of Climate, 10, 1154-1170 Murray-Tortarolo, G., Anav, A., Friedlingstein, P., Sitch, S., Piao, S., Zhu, Z., Poulter, B., Zaehle, S., Ahlström, A., Lomas, M., Levis, S., Viovy, N., \& Zeng, N. (2013). Evaluation of Land Surface Models in Reproducing Satellite-Derived LAI over the High-Latitude Northern Hemisphere. Part I: Uncoupled DGVMs. Remote Sensing, 5, 4819-4838

Myneni, R.B., Keeling, C.D., Tucker, C.J., Asrar, G., \& Nemani, R.R. (1997). Increased plant growth in the Northern high latitudes from 1981-1991. Nature, 386, 698-702

Myneni, R.B., \& Williams, D.L. (1994). On the relationship between FAPAR and NDVI. Remote sensing of the environment, 49, 200-211

Nagai, S., Inoue, T., Ohtsuka, T., Kobayashi, H., Kurumado, K., Muraoka, H., \& Nasahara, K.N. (2014). Relationship between spatio-temporal characteristics of leaf-fall phenology and seasonal 
648

649

650

651

652

653

654

655

656

657

658

659

660

661

662

663

664

665

666

667

668

669

670

671

672

variations in near surface- and satellite-observed vegetation indices in a cool-temperate deciduous broad-leaved forest in Japan. International Journal of Remote Sensing, 35, 3520-3536

Olsson, C., \& Jönsson, A.M. (2014). Process-based models not always better than empirical models for simulating budburst of Norway spruce and birch in Europe. Global Change Biology, 20, 34923507

Penuelas, J., Rutishauser, T., \& Filella, I. (2009). Phenology feedbacks on climate chnage. Science, $324,887-888$

Peñuelas, J., Rutishauser, T., \& Filella, I. (2009). Phenology feedbacks on climate change. Science, $324,887-888$

Pouliot, D., Latifovic, R., Fernandes, R., \& Olthof, I. (2011). Evaluation of compositing period and AVHRR and MERIS combination for improvement of spring phenology detection in deciduous forests. Remote Sensing of Environment, 115, 158-166

Reed, B.C., Brown, J.F., VanderZee, D., Loveland, T.R., Merchant, J.W., \& Ohlen, D.O. (1994).

Measuring phenological variability from satellite imagery. Journal of Vegetation Science, 5, 703714

Reich, P.B., Walters, M.B., \& Ellsworth, D.S. (1991). Leaf age and season influence the relationships between leaf nitrogen, leaf mass per area and photosynthesis in maple and oak trees. Plant, Cell \& Environment, 14, 251-259

Richardson, A.D., Anderson, R.S., Arain, M.A., Barr, A.G., Bohrer, G., Chen, G., Chen, J.M., Ciais, P., Davis, K.J., Desai, A.R., Dietze, M.C., Dragoni, D., Garrity, S.R., Gough, C.M., Grant, R., Hollinger, D.Y., Margolis, H.A., McCaughey, H., Migliavacca, M., Monson, R.K., Munger, J.W., Poulter, B., Raczka, B.M., Ricciuto, D.M., Sahoo, A.K., Schaefer, K., Tian, H., Vargas, R., Verbeeck, H., Xiao, J., \& Xue, Y. (2012). Terrestrial biosphere models need better representation of vegetation phenology: Results from the North American Carbon Program Site Synthesis. Global Change Biology, 18, 566-584 
673 Richardson, A.D., Braswell, B.H., Hollinger, D.Y., Jenkins, J.P., \& Ollinger, S.V. (2009). Near674 surface remote sensing of spatial and temporal variation in canopy phenology. Ecological 675 Applications, $19,1417-1428$

676 Richardson, A.D., Keenan, T.F., Migliavacca, M., Ryu, Y., Sonnentag, O., \& Toomey, M. (2013). 677 Climate change, phenology, and phenological control of vegetation feedbacks to the climate system. 678 Agricultural and Forest Meteorology, 169, 156-173

679 Rosemartin, A.H., Denny, E.G., Weltzin, J.F., Lee Marsh, R., Wilson, B.E., Mehdipoor, H., Zurita680 Milla, R., \& Schwartz, M.D. (2015). Lilac and honeysuckle phenology data 1956-2014. Scientific $681 \quad$ Data, 2, 150038

682 Sakamoto, T., Wardlow, B.D., Gitelson, A.A., Verma, S.B., Suyker, A.E., \& Arkebauer, T.J. 683 (2010). A Two-Step Filtering approach for detecting maize and soybean phenology with time-series 684 MODIS data. Remote Sensing of Environment, 114, 2146-2159

685 Samanta, A., Costa, M.H., Nunes, E.L., Vieira, S.A., Xu, L., \& Myneni, R.B. (2011). Comment on 686 "Drought-Induced Reduction in Global Terrestrial Net Primary Production from 2000 Through 687 2009”. Science, 333, 1093

688 Schneider, U., Becker, A., Finger, P., Meyer-Christoffer, A., Ziese, M., \& Rudolf, B. (2014). 689 GPCC's new land surface precipitation climatology based on quality-controlled in situ data and its 690 role in quantifying the global water cycle. Theoretical and Applied Climatology, 115, 15-40

691 Schwartz, M.D., \& Reiter, B.E. (2000). Changes in North American spring. International Journal 692 of Climatology, 20, 929-932

693 Sobrino, J.S., Julien, Y., \& Soria, G. (2013). Phenology Estimation From Meteosat Second 694 Generation Data. Selected Topics in Applied Earth Observations and Remote Sensing, IEEE 695 Journal of, 6, 1653-1659 
696

697

698

699

700

701

702

703

704

705

706

707

708

709

710

711

712

713

714

715

716

717

718

719

Steven, M.D., Malthus, T.J., \& Baret, F. (2015). Towards Standardisation of Vegetation Indices. In P.S. Thenkabail (Ed.), Land Resources Monitoring, Modeling, and Mapping with Remote Sensing: CRC Press

Stöckli, R., Rutishauser, T., Baker, I., Liniger, M.A., \& Denning, A.S. (2011). A global reanalysis of vegetation phenology. Journal of Geophysical Research: Biogeosciences, 116, G03020

Stöckli, R., Rutishauser, T., Dragoni, D., O'Keef, J., Thornton, P., Jolly, M., Lu, L., \& Denning, A.S. (2008). Remote sensing data assimilation for a prognositc phenology model. Journal of Geophysical Research, 113, 1-19

Tateishi, R., \& Ebata, M. (2004). Analysis of phenological change patterns using 1982-2000 Advanced Very High Resolution Radiometer (AVHRR) data. International Journal of Remote Sensing, 25, 2287-2300

Verbesselt, J., Hyndman, R., Newnham, G., \& Culvenor, D. (2010). Detecting trend and seasonal changes in satellite image time series. Remote Sensing of Environment, 114, 106-115

Verger, A., Baret, F., \& Weiss, M. (2011). A multisensor fusion approach to improve LAI time series. Remote Sensing of Enviroment, 115, 2460-2470

Verger, A., Baret, F., Weiss, M., Filella, I., \& Peñuelas, J. (2015). GEOCLIM: A global climatology of LAI, FAPAR, and FCOVER from VEGETATION observations for 1999-2010. Remote Sensing of Environment, 166, 126-137

Verger, A., Baret , F., Weiss, M., Kandasamy, S., \& Vermote, E. (2013). The CACAO method for smoothing, gap filling and characterizing seasonal anomalies in satellite time series. IEEE transactions on Geoscience and Remote Sensing, 51, 1963-1972

Verger, A., Vigneau, N., Corentin, C., Gilliot, J.M., Comar, A., \& Baret , F. (2014). Green area index from an unmanned aerial system over wheat and rapeseed crops. Remote Sensing of Environment, 152, 654-664 
Vrieling, A., de Leeuw, J., \& Said, M. (2013). Length of Growing Period over Africa: Variability and Trends from 30 Years of NDVI Time Series. Remote Sensing, 5, 982-1000

Weedon, G.P., Balsamo, G., Bellouin, N., Gomes, S., Best, M.J., \& Viterbo, P. (2014). The WFDEI meteorological forcing data set: WATCH Forcing Data methodology applied to ERA-Interim reanalysis data. Water Resources Research, 50, 7505-7514

White, K., Pontius, J., \& Schaberg, P. (2014). Remote sensing of spring phenology in northeastern forests: A comparison of methods, field metrics and sources of uncertainty. Remote Sensing of Environment, 148, 97-107

White, M.A., de Beurs, K.M., Didan, K., Inouye, D.W., Richardson, A.D., Jensen, O.P., O’Keefe, J., Zhang, G., Nemani, R.R., van Leeuwen, W.J.D., Brown, J.F., de Wit, A., Schaepman, M., Lin, X., Dettinger, M., Bailey, A.S., Kimbal, J., Schwartz, M.D., Baldocchi, D.D., Lee, J.T., \& Lauenroth, W.K. (2009). Intercomparison, interpretation, and assessment of spring phenology in North America estimated from remote sensing for 1982-2006 Global Change Biology, 15, $2335-2359$

White, M.A., Thornton, P.E., \& Running, S.W. (1997). A continental phenology model for monitoring vegetation responses to interannual climatic variability. Global Biogeochem. Cycles, 11, $217-234$

Wright, I.J., Reich, P.B., Westoby, M., Ackerly, D.D., Baruch, Z., Bongers, F., Cavender-Bares, J., Chapin, T., Cornelissen, J.H.C., Diemer, M., Flexas, J., Garnier, E., Groom, P.K., Gulias, J., Hikosaka, K., Lamont, B.B., Lee, T., Lee, W., Lusk, C., Midgley, J.J., Navas, M.-L., Niinemets, U., Oleksyn, J., Osada, N., Poorter, H., Poot, P., Prior, L., Pyankov, V.I., Roumet, C., Thomas, S.C., Tjoelker, M.G., Veneklaas, E.J., \& Villar, R. (2004). The worldwide leaf economics spectrum. Nature, 428, 821 
743 Wu, C., Gonsamo, A., Gough, C.M., Chen, J.M., \& Xu, S. (2014). Modeling growing season 744 phenology in North American forests using seasonal mean vegetation indices from MODIS. Remote 745 Sensing of Environment, 147, 79-88

746 Zhang, X., Friedl, M.A., \& Schaaf, C.B. (2006). Global vegetation phenology from Moderate 747 Resolution Imaging Spectroradiometer (MODIS): Evaluation of global patterns and comparison 748 with in situ measurements. Journal of Geophysical Research: Biogeosciences, 111, G04017

749 Zhang, X., Friedl, M.A., \& Schaaf, C.B. (2009). Sensitivity of vegetation phenology detection to 750 the temporal resolution of satellite data. International Journal of Remote Sensing, 30, 2061-2074

751 Zhang, X., Friedl, M.A., Schaaf, C.B., \& Strahler, A.H. (2004). Climate controls on vegetation 752 phenological patterns in northern mid- and high latitudes inferred from MODIS data. Global 753 Change Biology, 10, 1133-1145

754 Zhang, X., Friedl, M.A., Schaaf, C.B., Strahler, A.H., Hodges, J.C.F., Gao, F., Reed, B.C., \& Huete, 755 A. (2003). Monitoring vegetation phenology using MODIS. Remote Sensing of Environment, 84, $756 \quad 471-475$

757 Zhang, X., Tan, B., \& Yu, Y. (2014). Interannual variations and trends in global land surface 758 phenology derived from enhanced vegetation index during 1982-2010. International Journal of 759 Biometeorology, 58, 547-564

760 Zhu, Z., Bi, J., Pan, Y., Ganguly, S., Anav, A., Xu, L., Samanta, A., Piao, S., Nemani, R., \& 761 Myneni, R. (2013). Global Data Sets of Vegetation Leaf Area Index (LAI)3g and Fraction of 762 Photosynthetically Active Radiation (FPAR)3g Derived from Global Inventory Modeling and 763 Mapping Studies (GIMMS) Normalized Difference Vegetation Index (NDVI3g) for the Period 7641981 to 2011. Remote Sensing, 5, 927-948 


\section{List of Figure Captions}

768 Figure 1. Illustration of phenological metrics (amplitude, start (SoS), end (EoS), and length (LoS) 769 of the growing season) computed from GEOCLIM-LAI over a cropland site at $45^{\circ} \mathrm{N}$ and $19^{\circ} \mathrm{E}$ (a) 770 and a grassland site at $27^{\circ} \mathrm{S}$ and $27^{\circ} \mathrm{E}(\mathrm{b})$. DOY, day of year.

771

Figure 2. Location of ground phenological observations of (a) S. vulgaris in USA for the range of latitudes 35-37.5 (o), 37.5-40 (+), 40-42.5 (×), 42.5-45 (口) and 45-48 ( $\diamond)$, and (b) B. pendula in Slovenia-Croatia (o), Germany (+), Lithuania ( $\times$ ) and Finland (for latitudes below $65^{\circ}(\square)$ and above $\left.65^{\circ}(\diamond)\right)$

Figure 3. Flow chart describing the approach for evaluating the climatologies (grey boxes) of phenological metrics derived from ground data, GEOCLIM-LAI, MODIS-EVI, MODIS-NDVI, and climatic variables (air temperature, rainfall and short-wave radiation). The original products are indicated in rectangular white boxes, the methods in ellipses. The horizontal and vertical arrows indicate the spatial and temporal scales, respectively.

Figure 4. Maps of (a) the amplitude of GEOCLIM-LAI, and (b) the number of growing seasons derived from GEOCLIM-LAI. The dark grey areas correspond to pixels with missing data.

Figure 5. Direct validation of phenologies derived from GEOCLIM-LAI (top) and MODIS-EVI (bottom) for the start of season (SoS) (plots a, b, e and f), end of season (EoS) (plots c and g), and length of season (LoS) (plots $\mathrm{d}$ and $\mathrm{h}$ ) compared to available ground-based observations on the day of full leaf of lilac (S. vulgaris) in USA, and day of budburst and 50\% autumnal colouring of leaves of birch (B. pendula) in Europe. See Figure 3 for the location of the data and the legend. The statistics of the comparison are provided in Table 1.

Figure 6. Global maps of the differences (in days) between the average phenologies derived from GEOCLIM-LAI and MODIS-EVI for the (a) start of season, (b) end of season, and (c) length of season. Red (blue) indicates a delay (advance) in phenological events or longer (shorter) seasons for 
GEOCLIM-LAI compared to MODIS-EVI. The light-grey areas correspond to pixels with any growing season (Figure 4b). The dark-grey areas correspond to pixels with missing data.

Figure 7. Bias (in days) of the start of season derived from GEOCLIM-LAI compared to that from MODIS-EVI as a function of (a) the amplitude of GEOCLIM-LAI (Figure 4a). The bold line corresponds to the median value of the bias. The grey areas correspond to $75 \%$ (dark grey), $85 \%$ (medium grey), and 95\% (light grey) of the population of values for a given seasonality. Analysis at the global scale over 35627 pixels at a spatial sampling of $0.5^{\circ}$. (b) Theoretical differences as a function of the rate of change in the EVI.

Figure 8. Maps of phenological metrics for the (a) start, (b) end and (c) length of season derived from GEOCLIM-LAI. Areas with any growing season are shaded in light grey. The dark-grey areas correspond to pixels with missing data. DOY, day of year.

Figure 9. Latitudinal transects at resolution of 0.5 degrees of the average length of season (LoS) derived from GEOCLIM-LAI, mean annual air temperature (Tair), cumulative annual rainfall (Rainfall), and mean annual short-wave downwards surface radiation (SW). The LoS was not plotted when the fraction of the land pixels used to compute the average phenological metric was lower than $0.1 \%$ of the total land pixels.

Figure 10. Maps of the start of season (SoS) derived from GEOCLIM-LAI in (a) Europe and (b) African Sahel. The dashed back box in Sudano-Sahelian West Africa covering much of the southern half of Mali corresponds to the study area for the evaluation of the latitudinal gradients of phenology (Figure 11b). Areas with any growing season are shaded in light grey. DOY, day of year. Figure 11. Latitudinal gradients of the average phenological metrics for the start (o), end ( $\square$ ), and length $(\diamond)$ of season in units of day of year (DOY) in (a) Europe at ground selected sites of $B$. pendula (Figure 2b) as observed at the plot level (open symbols) and derived from GEOCLIM-LAI 
814 (filled symbols), and (b) Sudano-Sahelian West Africa (Figure 10b) as derived from MODIS-NDVI 815 (open symbols) and GEOCLIM-LAI (filled symbols). 
816 Table 1. Statistics of the comparisons between GEOCLIM-LAI derived phenologies for the start of 817 season $(\mathrm{SoS})$, end of season $(\mathrm{EoS})$, and length of season $(\mathrm{LoS})$ and the ground observations for 818 different phenological metric definitions based on specific thresholds $(10,20,30,40$, and $50 \%)$ of 819 the LAI amplitude and the first derivative criteria (1st Der.). The statistics of the validation of the 820 climatology of MODIS-EVI phenology are also indicated. $n$ : number of available ground 821 observations. RMSE: root mean square error. Bias: average difference between the satellite derived 822 phenologies minus the observed date (positive bias indicates that the SoS and EoS occurred later 823 than the observed leaf-out and autumnal colouring, respectively, and the LoS is longer than the 824 actual duration of the growing season). R: correlation coefficient. * mark indicates significant 825 correlations with $\mathrm{p}<0.05(* *$ indicates $\mathrm{p}<0.001)$. Slope and offset of the regression line computed at $826 \mathrm{p}=0.05$. Numbers in bold refer to the selected method.

\begin{tabular}{|c|c|c|c|c|c|c|c|}
\hline Species & Metric & Definition & $\begin{array}{l}\text { RMSE } \\
\text { (days) }\end{array}$ & $\begin{array}{l}\text { Bias } \\
\text { (days) }\end{array}$ & $\mathrm{R}$ & Slope & $\begin{array}{l}\text { Offset } \\
\text { (days) }\end{array}$ \\
\hline \multirow{7}{*}{$\begin{array}{l}\text { S. vulgaris } \\
(\mathrm{n}=52)\end{array}$} & \multirow[t]{7}{*}{ SoS } & $10 \%$ & 47.34 & -16.38 & 0.26 & 0.68 & 20.53 \\
\hline & & $20 \%$ & 27.56 & -14.26 & $0.35^{*}$ & 0.46 & 47.16 \\
\hline & & $30 \%$ & 18.92 & -2.69 & $0.5 * *$ & 0.54 & 50.02 \\
\hline & & $40 \%$ & 19.11 & 3.68 & $0.51 * *$ & 0.57 & 52.74 \\
\hline & & $50 \%$ & 21.01 & 10.32 & $0.52 * *$ & 0.57 & 59.02 \\
\hline & & 1st Der. & 22.07 & 10.19 & $0.49 * *$ & 0.57 & 59.58 \\
\hline & & MODIS & 28.22 & -21.24 & $0.46^{* *}$ & 0.46 & 40.1 \\
\hline \multirow{22}{*}{$\begin{array}{l}\text { B. pendula } \\
(\mathrm{n}=59)\end{array}$} & \multirow[t]{7}{*}{ SoS } & $10 \%$ & 27.82 & -22.15 & $0.76^{* *}$ & 1.07 & -30.83 \\
\hline & & $20 \%$ & 14.61 & -8.54 & $0.86^{* *}$ & 1.07 & -17.36 \\
\hline & & $30 \%$ & 7.22 & 0.66 & $0.95 * *$ & 1.12 & -13.66 \\
\hline & & $40 \%$ & 27.27 & 10.44 & $0.58 * *$ & 0.97 & 14.43 \\
\hline & & $50 \%$ & 14.78 & 13.08 & $0.95 * *$ & 1.11 & 0.42 \\
\hline & & 1st Der. & 15.78 & 13.44 & $0.94 * *$ & 1.14 & -2.66 \\
\hline & & MODIS & 17.59 & -12.42 & $0.84 * *$ & 1.04 & -16.97 \\
\hline & \multirow[t]{7}{*}{ EoS } & $10 \%$ & 44.84 & 43.03 & $0.8^{* *}$ & 0.88 & 75.91 \\
\hline & & $20 \%$ & 33.49 & 31.27 & $0.81 * *$ & 0.85 & 72.82 \\
\hline & & $30 \%$ & 23.08 & 19.76 & $0.79 * *$ & 0.77 & 81.92 \\
\hline & & $40 \%$ & 15.00 & 6.59 & $0.72 * *$ & 0.66 & 99.00 \\
\hline & & $50 \%$ & 23.74 & -10.46 & $0.39^{*}$ & 0.41 & 147.63 \\
\hline & & 1st Der. & 45.16 & -12.05 & $0.28 *$ & 0.67 & 77.36 \\
\hline & & MODIS & 59.64 & 24.78 & 0.12 & 0.34 & 202.23 \\
\hline & \multirow[t]{8}{*}{$\mathrm{LoS}$} & $10 \%$ & 69.61 & 65.19 & $0.84 * *$ & 1.07 & 54.81 \\
\hline & & $20 \%$ & 44.13 & 39.81 & $0.89 * *$ & 1.06 & 31.29 \\
\hline & & $30 \%$ & 23.89 & 19.1 & $0.93 * *$ & 1.04 & 13.12 \\
\hline & & $40 \%$ & 27.12 & -3.85 & $0.76^{* *}$ & 0.89 & 12.94 \\
\hline & & $50 \%$ & 31.48 & -23.54 & $0.82 * *$ & 0.78 & 9.14 \\
\hline & & $30-40 \%$ & 15.71 & 5.93 & $0.92 * *$ & 0.97 & 11.12 \\
\hline & & 1st Der. & 50.22 & -25.49 & $0.61 * *$ & 0.95 & -18.07 \\
\hline & & MODIS & 68.05 & 37.6 & $0.42 *$ & 0.73 & 78.95 \\
\hline
\end{tabular}


Table 2. Statistics of a per class comparison between GEOCLIM-LAI and MODIS-EVI average 829 phenologies for the start of season (SoS), end of season (EoS), and length of season (LoS) at the 830 global scale over $n=35627$ pixels at a spatial sampling of $0.5^{\circ} \times 0.5^{\circ} . n$ : Number of pixels. RMSE: root mean square error. Bias: average difference between GEOCLIM-LAI minus MODIS-EVI 832 phenologies (negative (positive) bias indicates earlier (later) EoS (SoS) and shorter LoS for 833 GEOCLIM-LAI). Correlation coefficient $(R)$. *** mark indicates significant correlations with $\mathrm{p}<10^{-}$ 834 ${ }^{6}$. Slope and offset of the regression line computed at $\mathrm{p}=0.05$ significance level. Analysis per biome 835 classes based on GLOBCOVER (Defourny et al. 2009) land-cover map.

836

\begin{tabular}{lllllll}
\hline Biome class & Metric & $\begin{array}{l}\text { RMSE } \\
\text { (days) }\end{array}$ & $\begin{array}{l}\text { Bias } \\
\text { (days) }\end{array}$ & R*** & Slope & $\begin{array}{l}\text { Offset } \\
\text { (days) }\end{array}$ \\
\hline Shrub/Savannah & SoS & 34.49 & 5.37 & 0.86 & 1.03 & 0.63 \\
$(\mathrm{n}=10450)$ & EoS & 28.85 & -7.77 & 0.84 & 1.00 & -7.93 \\
& LoS & 38.79 & -14.6 & 0.81 & 0.63 & 37.03 \\
\hline Crop/Grassland & SoS & 40.01 & 11.00 & 0.86 & 0.91 & 24.6 \\
$(\mathrm{n}=12965)$ & EoS & 46.66 & -13.74 & 0.75 & 0.88 & 16.58 \\
& LoS & 51.44 & -31.79 & 0.68 & 0.64 & 31.43 \\
\hline Decideous Broadleaf & SoS & 27.79 & 19.65 & 0.96 & 1.06 & 11.45 \\
Forest & EoS & 28.68 & -20.45 & 0.91 & 0.94 & -4.83 \\
(n=4000) & LoS & 42.38 & -33.56 & 0.87 & 0.75 & 14.29 \\
\hline Needleleaf Forest & SoS & 11.03 & 7.22 & 0.79 & 0.68 & 51.52 \\
(n=7345) & EoS & 9.42 & -5.34 & 0.79 & 0.72 & 66.83 \\
& LoS & 18.82 & -12.06 & 0.80 & 0.72 & 21.32 \\
\hline All biomes & SoS & 30.79 & 9.38 & 0.88 & 0.97 & 14.07 \\
(n=35627) & EoS & 30.88 & -11.8 & 0.84 & 0.96 & -2.16 \\
& LoS & 40.31 & -21.51 & 0.80 & 0.67 & 29.28 \\
\hline
\end{tabular}

837 
a

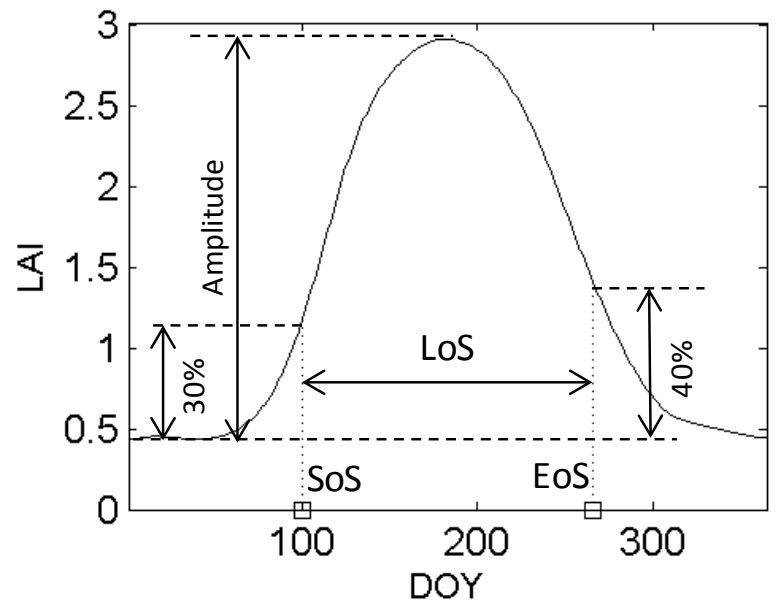

b

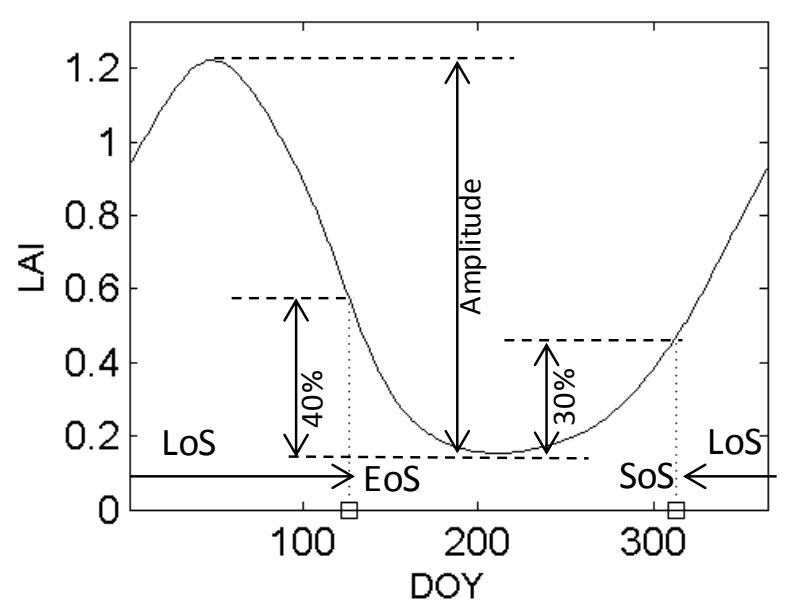

845

846

847

848

849

850 851

852

853

854

855

856

857

858

859 854

Figure 1. Illustration of phenological metrics (amplitude, start (SoS), end (EoS), and length (LoS) of the growing season) computed from GEOCLIM-LAI over a cropland site at $45^{\circ} \mathrm{N}$ and $19^{\circ} \mathrm{E}$ (a) and a grassland site at $27^{\circ} \mathrm{S}$ and $27^{\circ} \mathrm{E}(\mathrm{b})$. DOY, day of year. 850 53 

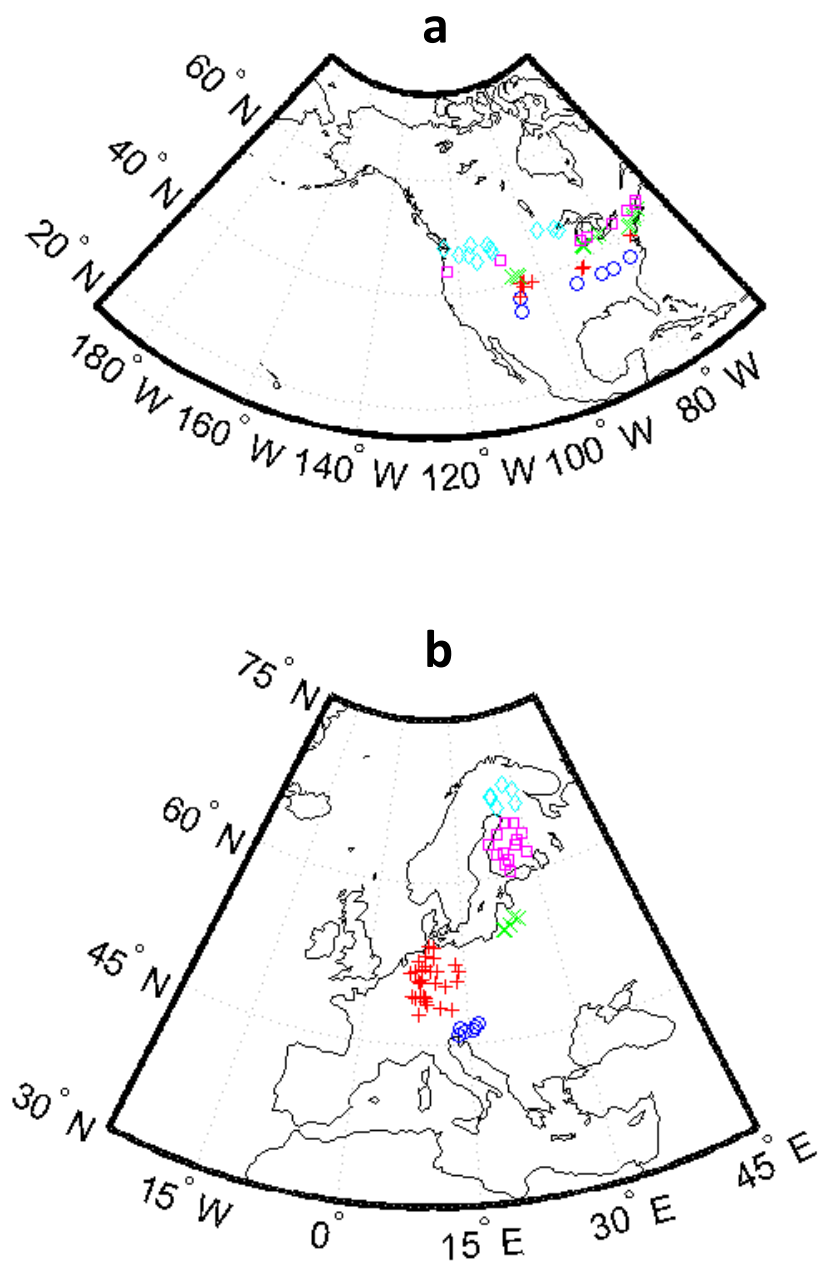

860

861 Figure 2. Location of ground phenological observations of (a) S. vulgaris in USA for the range of

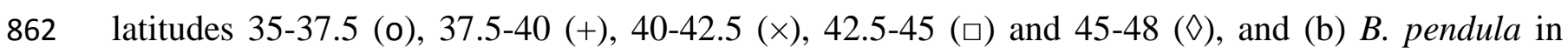
863 Slovenia-Croatia (o), Germany (+), Lithuania ( $\times$ ) and Finland (for latitudes below $65^{\circ}(\square)$ and above $\left.86465^{\circ}(\diamond)\right)$. 


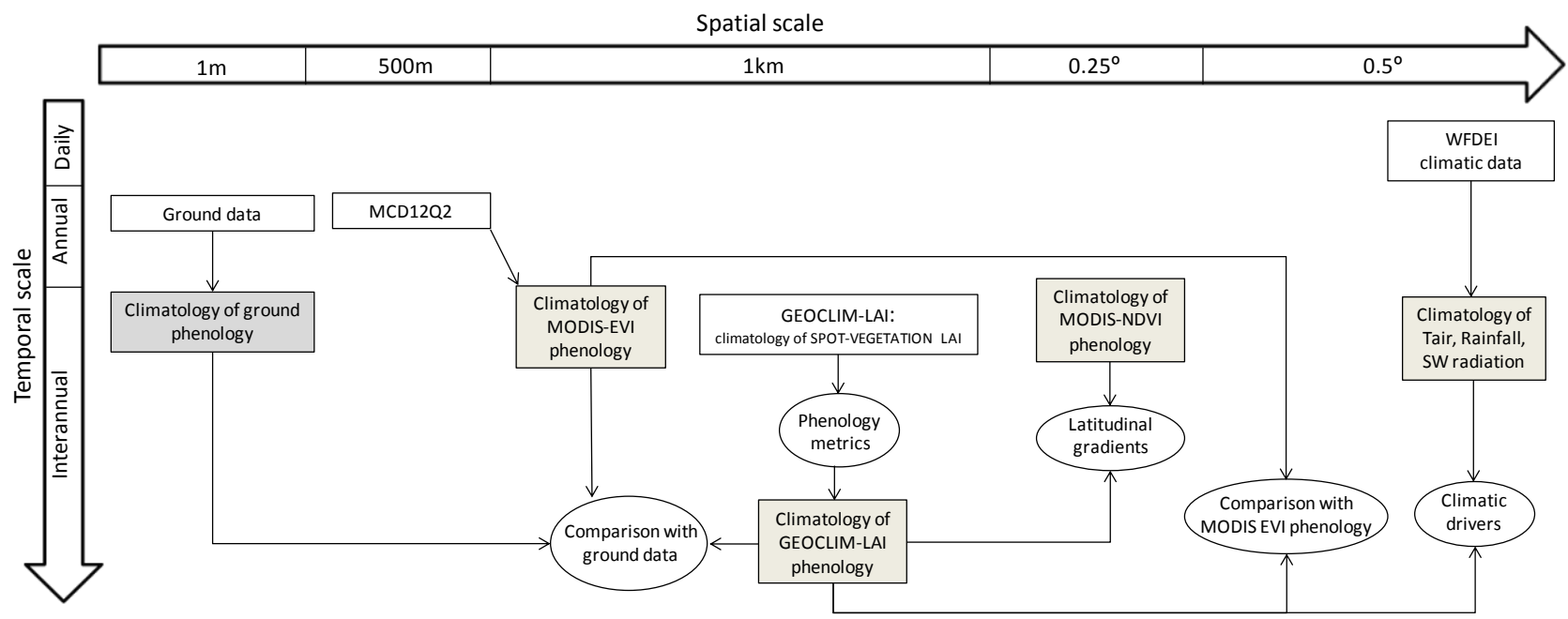

868 Figure 3. Flow chart describing the approach for evaluating the climatologies (grey boxes) of 869 phenological metrics derived from ground data, GEOCLIM-LAI, MODIS-EVI, MODIS-NDVI, and 870 climatic variables (air temperature, rainfall and short-wave radiation). The original products are 871 indicated in rectangular white boxes, the methods in ellipses. The horizontal and vertical arrows 872 indicate the spatial and temporal scales, respectively. 

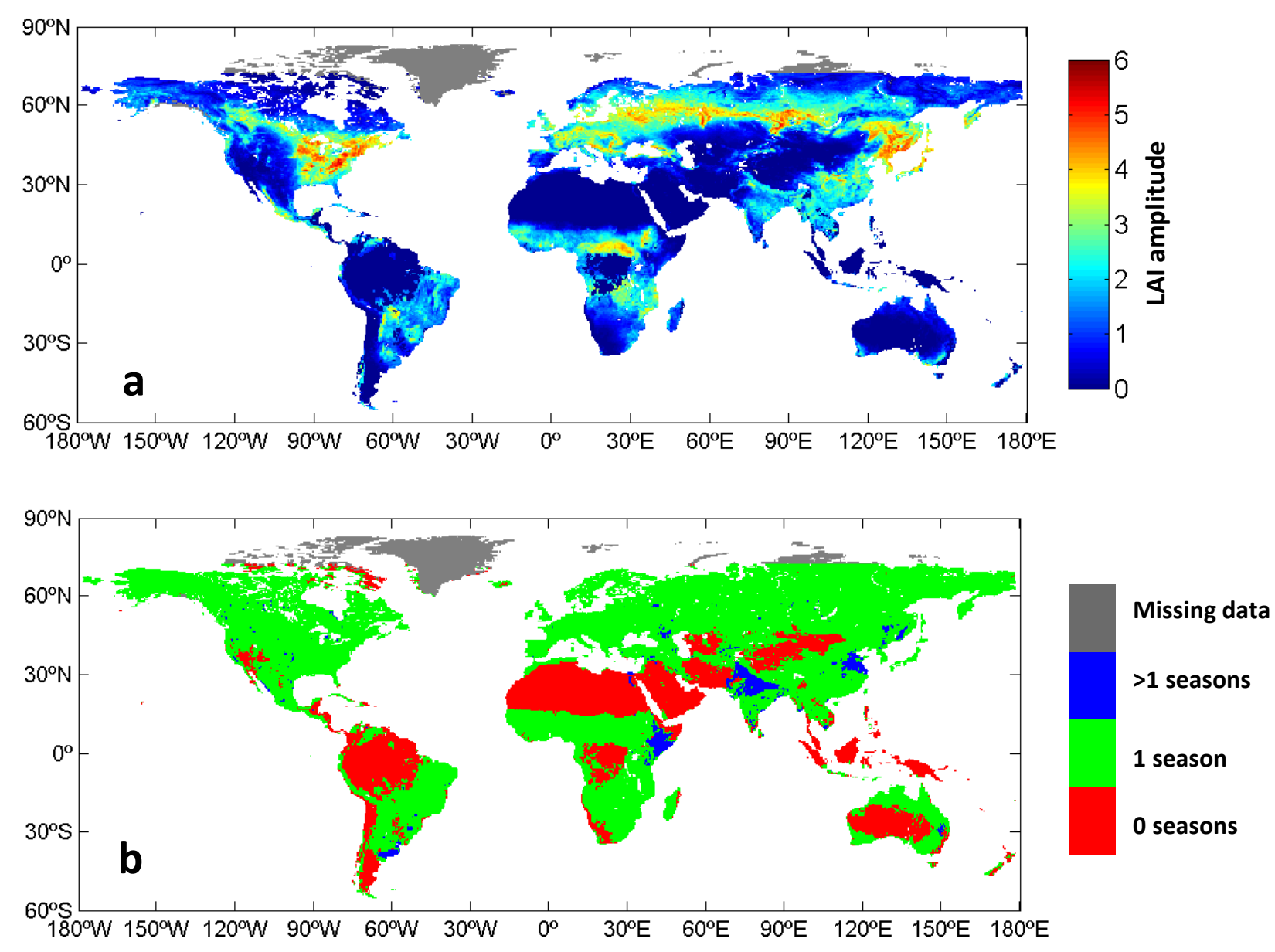

876 Figure 4. Maps of (a) the amplitude of GEOCLIM-LAI, and (b) the number of growing seasons 877 derived from GEOCLIM-LAI. The dark grey areas correspond to pixels with missing data. 
S. vulgaris (USA)
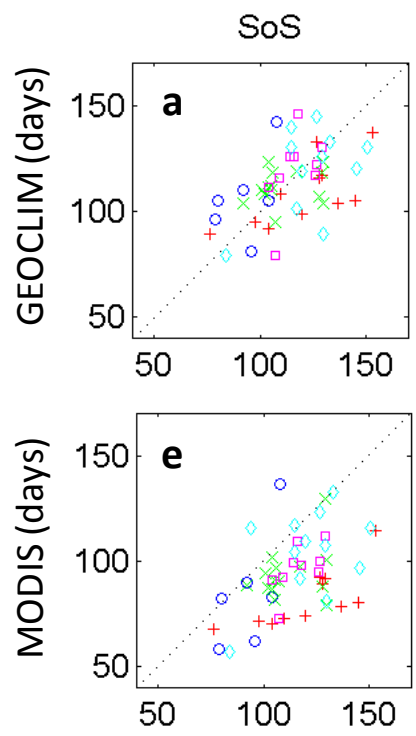

879

880

881

882

883

884

885

886

887

888

889

890

\section{B. pendula (Europe)}
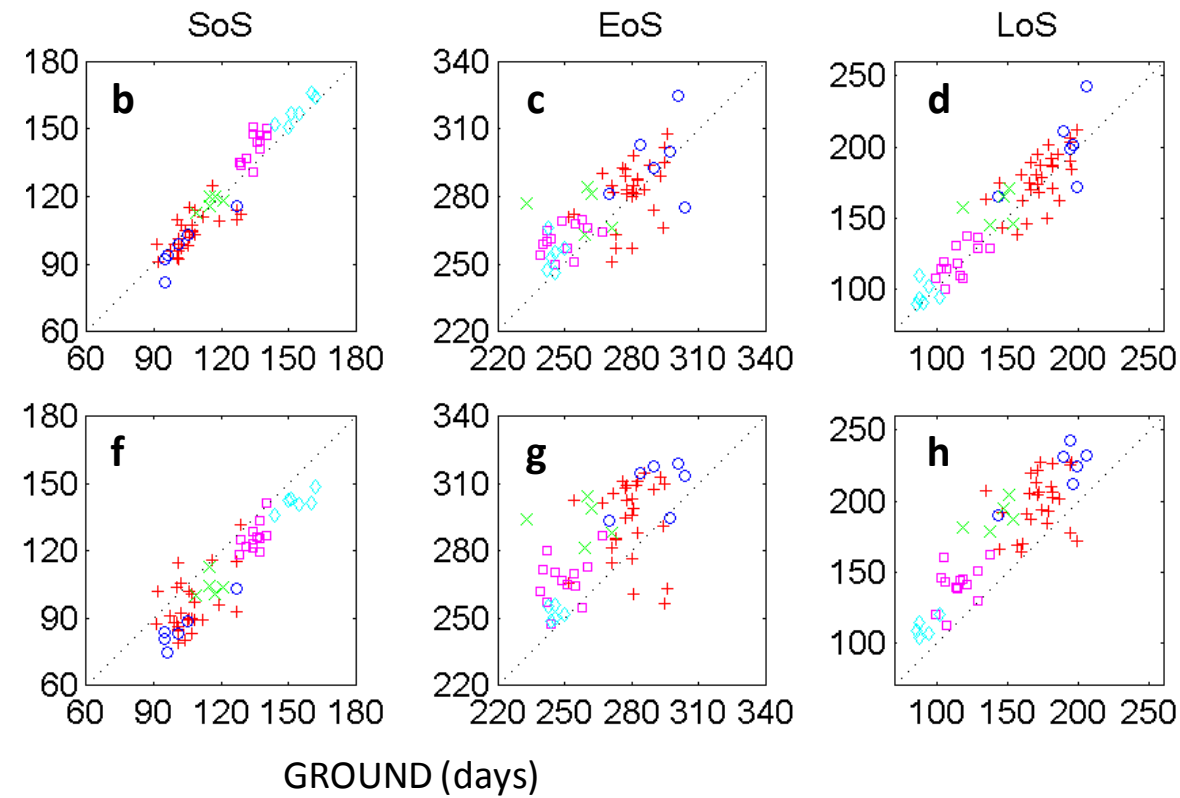

Figure 5. Direct validation of phenologies derived from GEOCLIM-LAI (top) and MODIS-EVI (bottom) for the start of season (SoS) (plots a, b, e and f), end of season (EoS) (plots c and g), and length of season (LoS) (plots $d$ and $h$ ) compared to available ground-based observations on the day of full leaf of lilac (S. vulgaris) in USA, and day of budburst and 50\% autumnal colouring of leaves of birch (B. pendula) in Europe. See Figure 3 for the location of the data and the legend. The statistics of the comparison are provided in Table 1. 

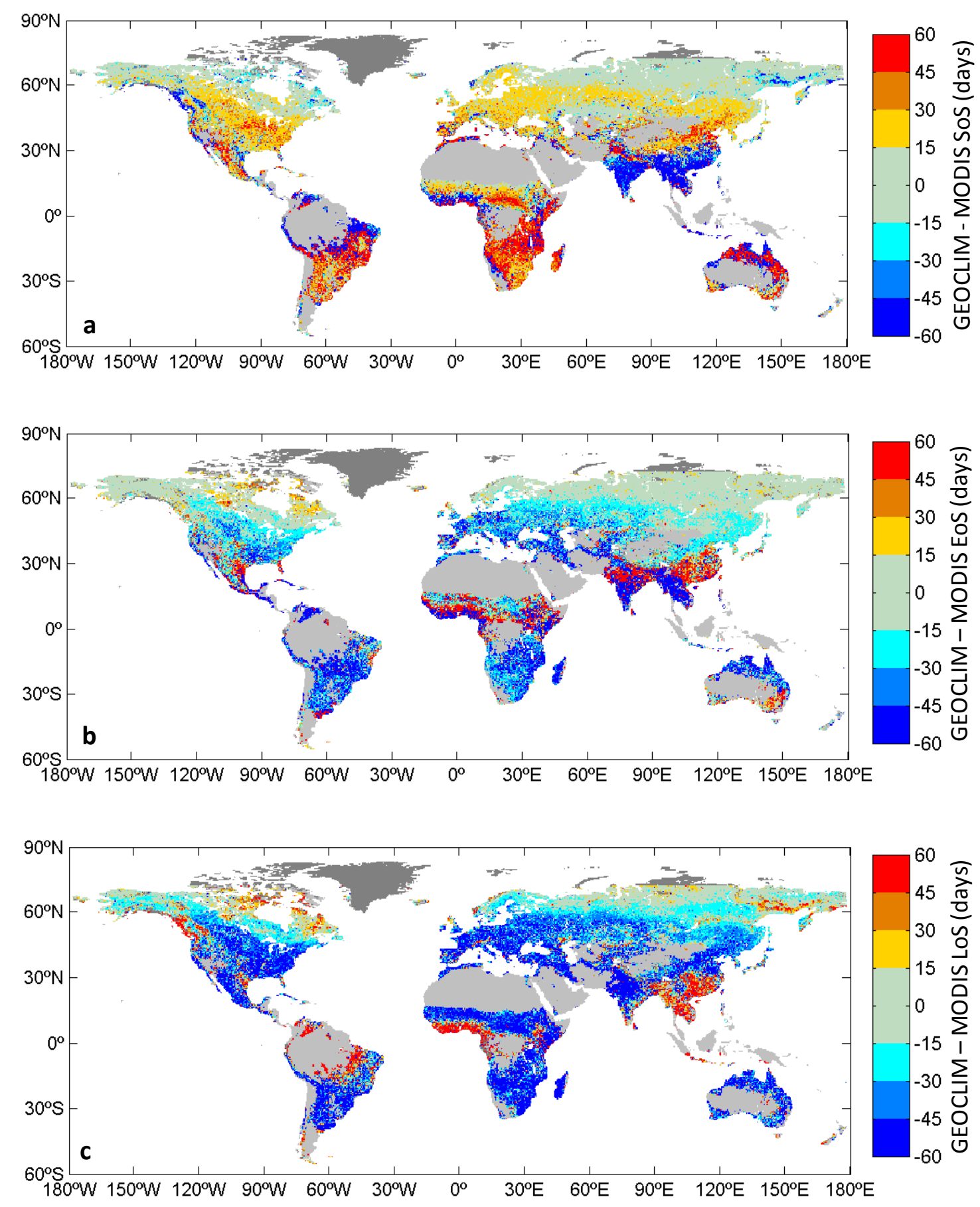

892 Figure 6. Global maps of the differences (in days) between the average phenologies derived from 893 GEOCLIM-LAI and MODIS-EVI for the (a) start of season, (b) end of season, and (c) length of 894 season. Red (blue) indicates a delay (advance) in phenological events or longer (shorter) seasons for 895 GEOCLIM-LAI compared to MODIS-EVI. The light-grey areas correspond to pixels with any 896 growing season (Figure 4b). The dark-grey areas correspond to pixels with missing data. 
a

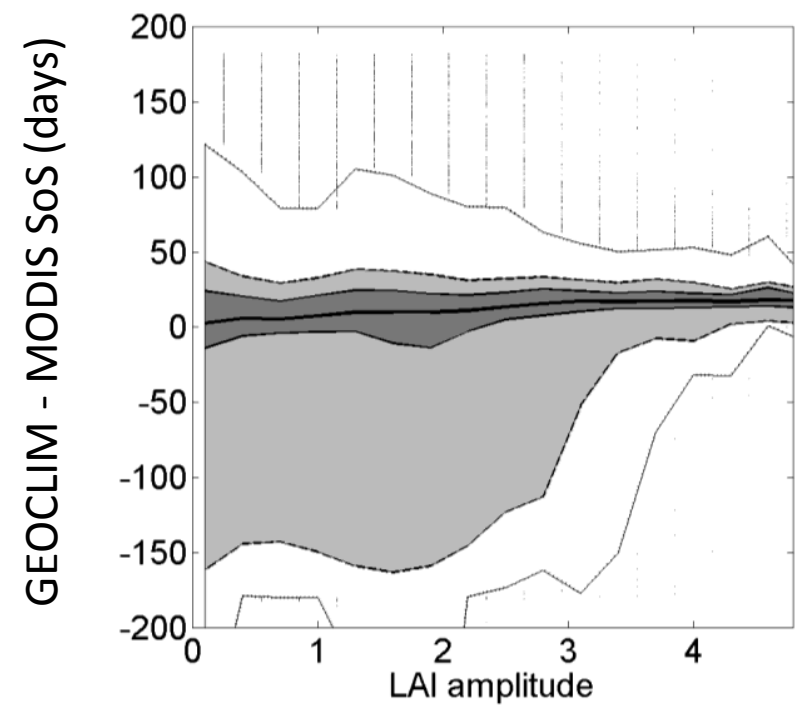

b

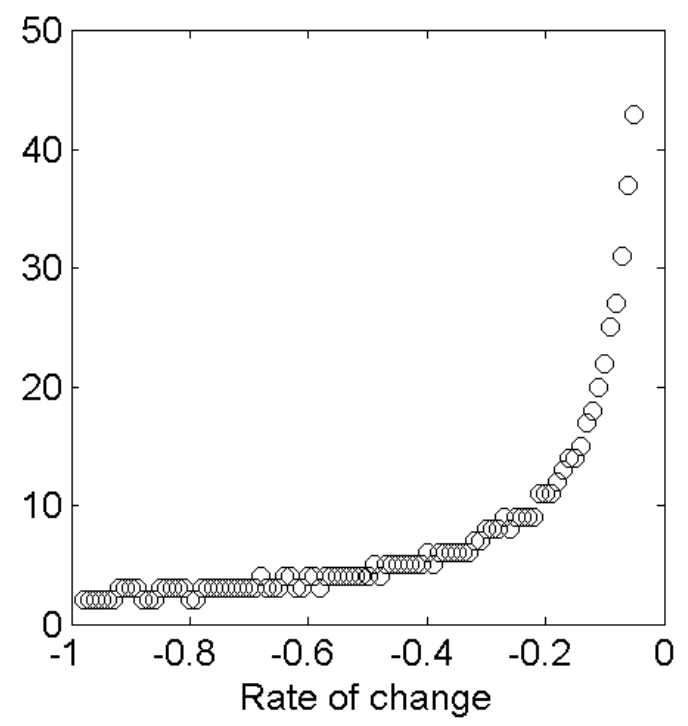

898

899 Figure 7. Bias (in days) of the start of season derived from GEOCLIM-LAI compared to that from 900 MODIS-EVI as a function of (a) the amplitude of GEOCLIM-LAI (Figure 4a). The bold line 901 corresponds to the median value of the bias. The grey areas correspond to $75 \%$ (dark grey), $85 \%$ 902 (medium grey), and 95\% (light grey) of the population of values for a given seasonality. Analysis at 903 the global scale over 35627 pixels at a spatial sampling of $0.5^{\circ}$. (b) Theoretical differences as a 904 function of the rate of change in the EVI.

905

906

907

908

909

910 

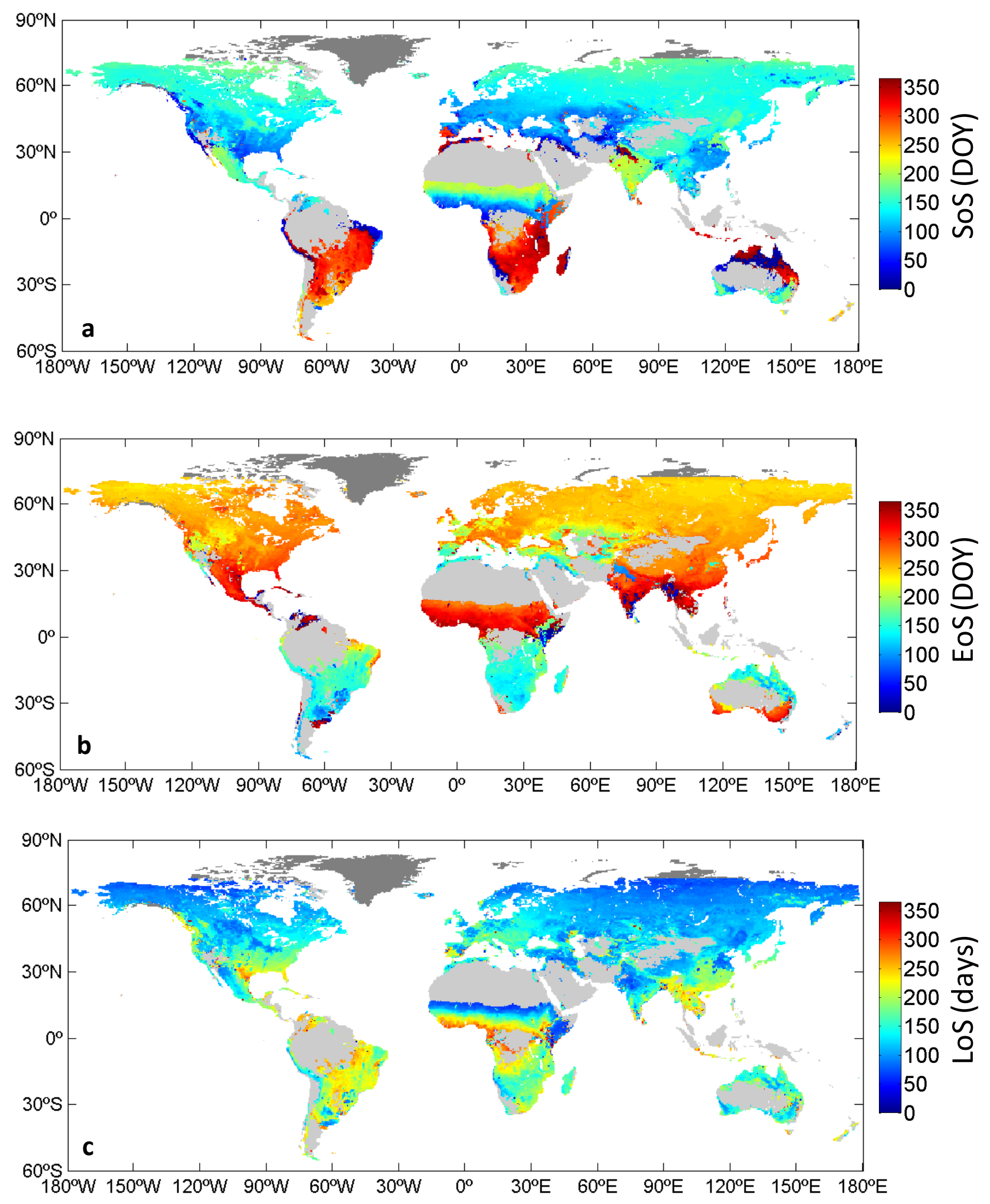

913 Figure 8. Maps of phenological metrics for the (a) start, (b) end and (c) length of season derived 914 from GEOCLIM-LAI. Areas with any growing season are shaded in light grey. The dark-grey areas 915 correspond to pixels with missing data. DOY, day of year. 


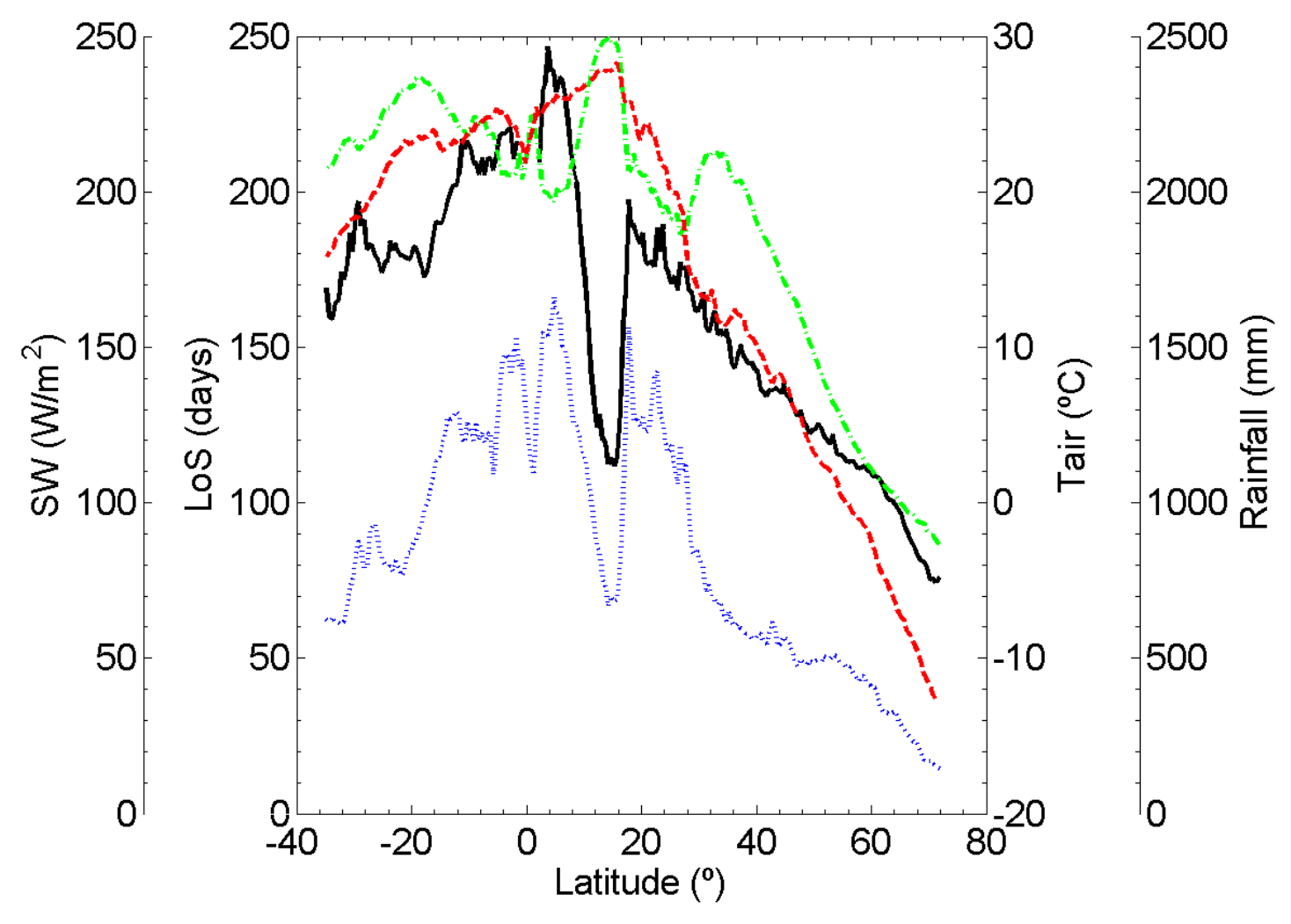

916

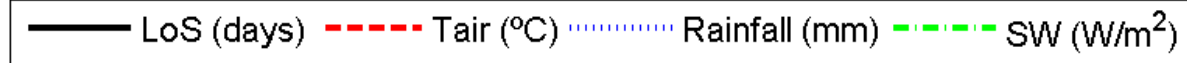

917 Figure 9. Latitudinal transects at resolution of 0.5 degrees of the average length of season (LoS)

918 derived from GEOCLIM-LAI, mean annual air temperature (Tair), cumulative annual rainfall 919 (Rainfall), and mean annual short-wave downwards surface radiation (SW). The LoS was not 920 plotted when the fraction of the land pixels used to compute the average phenological metric was 921 lower than $0.1 \%$ of the total land pixels. 


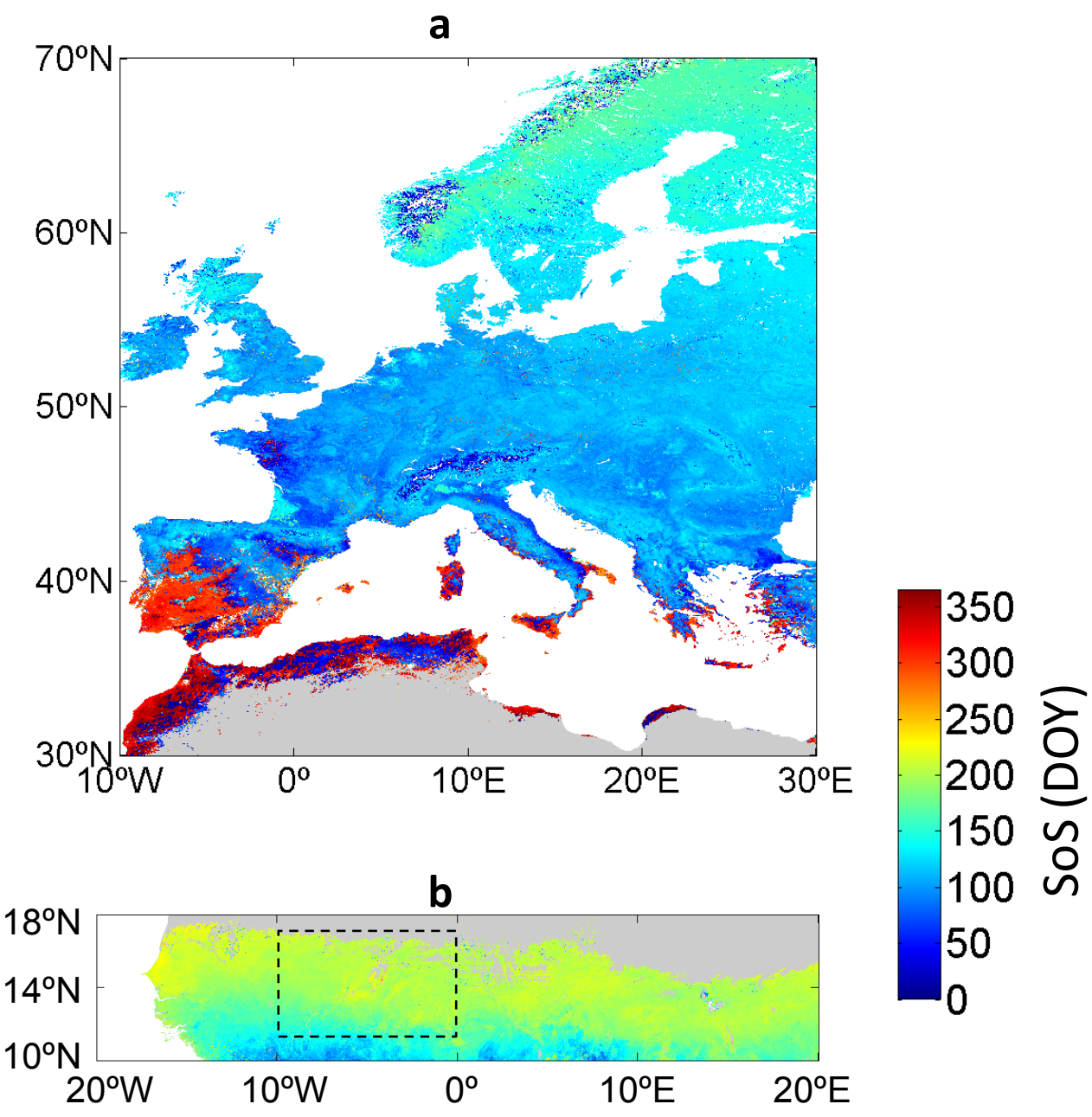

923 Figure 10. Maps of the start of season (SoS) derived from GEOCLIM-LAI in (a) Europe and (b) 924 African Sahel. The dashed back box in Sudano-Sahelian West Africa covering much of the southern 925 half of Mali corresponds to the study area for the evaluation of the latitudinal gradients of 926 phenology (Figure 11b). Areas with any growing season are shaded in light grey. DOY, day of year. 
a

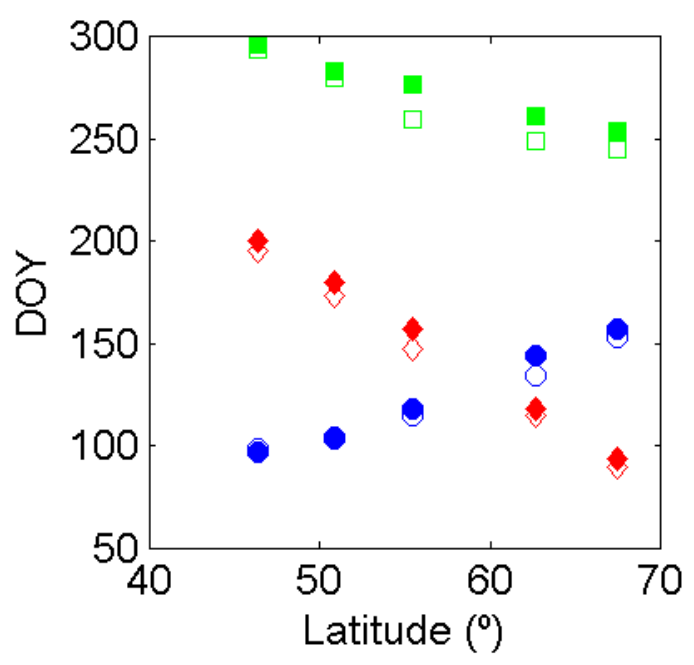

b

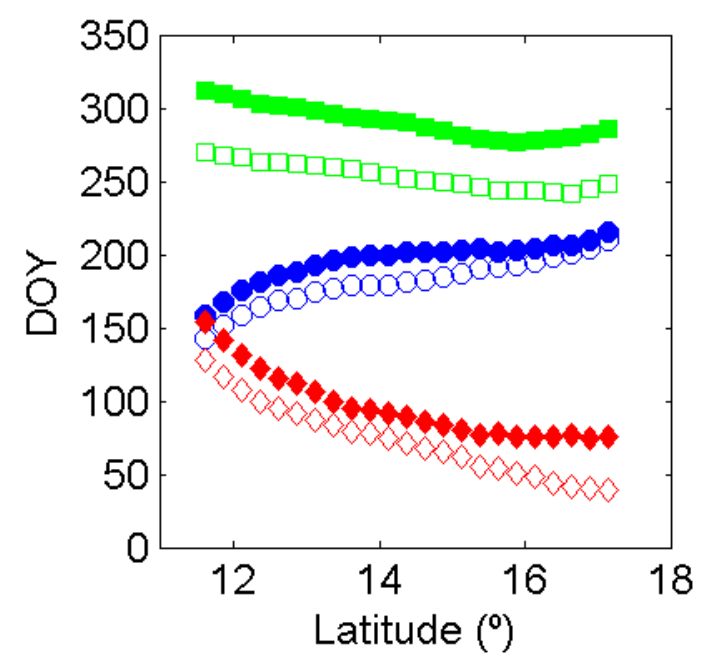

\section{o SoS $\square$ EOS $\diamond$ LoS}

933 Figure 11. Latitudinal gradients of the average phenological metrics for the start (o), end ( $\square$ ), and 934 length $(\diamond)$ of season in units of day of year (DOY) in (a) Europe at ground selected sites of $B$. 935 pendula (Figure 2b) as observed at the plot level (open symbols) and derived from GEOCLIM-LAI 936 (filled symbols), and (b) Sudano-Sahelian West Africa (Figure 10b) as derived from MODIS-NDVI 937 (open symbols) and GEOCLIM-LAI (filled symbols). 